\title{
Enterohemorrhagic E. coli alters murine intestinal epithelial tight junction protein expression and barrier function in a Shiga toxin independent manner
}

\author{
Jennifer L Roxas ${ }^{1}$, Athanasia Koutsouris ${ }^{1}$, Amy Bellmeyer ${ }^{1}$, Samuel Tesfay ${ }^{1}$, Sandhya Royan ${ }^{1}$, Kanakeshwari Falzari ${ }^{1}$, \\ Antoneicka Harris ${ }^{1}$, Hao Cheng ${ }^{1}$, Ki Jong Rhee ${ }^{1}$ and Gail Hecht ${ }^{1,2}$
}

\begin{abstract}
Shiga toxin (Stx) is implicated in the development of hemorrhagic colitis and hemolytic-uremic syndrome, but early symptoms of enterohemorrhagic Escherichia coli (EHEC) infection such as nonbloody diarrhea may be Stx independent. In this study, we defined the effects of EHEC, in the absence of Stx, on the intestinal epithelium using a murine model. EHEC colonization of intestines from two groups of antibiotic-free and streptomycin-treated C57BI/6J mice were characterized and compared. EHEC colonized the cecum and colon more efficiently than the ileum in both groups; however, greater amounts of tissue-associated EHEC were detected in streptomycin-pretreated mice. Imaging of intestinal tissues of mice infected with bioluminescent EHEC further confirmed tight association of the bacteria with the cecum and colon. Greater numbers of EHEC were also cultured from stool samples obtained from streptomycin-pretreated mice, as compared with those that received no antibiotics. Transmission electron microscopy shows that EHEC infection leads to microvillous effacement of mouse colonocytes. Hematoxylin and eosin staining of the colonic tissues of infected mice revealed a slight increase in the number of lamina propria polymorphonuclear leukocytes. Transmucosal electrical resistance, a measure of epithelial barrier function, was reduced in the colonic tissues of infected animals. Increased mucosal permeability to 4kDa FITC-dextran was also observed in the colonic tissues of infected mice. Immunofluorescence microscopy showed that EHEC infection resulted in redistribution of the tight junction (TJ) proteins occludin and claudin-3 and increased the expression of claudin-2, whereas ZO-1 localization remained unaltered. Quantitative real-time PCR showed that EHEC altered mRNA transcription of OCLN, CLDN2, and CLDN3. Most notably, claudin-2 expression was significantly increased and correlated with increased intestinal permeability. Our data indicate that C57BI/6J mice serve as an in vivo model to study the physiological effects of EHEC infection on the intestinal epithelium and suggest that altered transcription of TJ proteins has a role in the increase in intestinal permeability.
\end{abstract}

Laboratory Investigation (2010) 90, 1152-1168; doi:10.1038/labinvest.2010.91; published online 17 May 2010

KEYWORDS: mice; claudin-2; claudin-3; EHEC; occludin; microvilli effacement; transmucosal electrical resistance

Enterohemorrhagic Escherichia coli (EHEC) belongs to a family of pathogenic bacteria that produce attaching and effacing (A/E) lesions used to colonize host intestinal mucosa. ${ }^{1}$ Attachment of EHEC to the apical epithelial surface leads to recruitment of cytoskeletal proteins and injection of effector molecules directly into the host cell through the type III secretion system. The A/E phenotype results from the expression of virulence genes housed in the locus of enterocyte effacement pathogenicity island that encode proteins for the type III secretion system, intimin, and secreted effector proteins. ${ }^{2}$
Shiga toxin (Stx) is one of the major virulence factors produced by EHEC, and can cause microvascular endothelial injury. Stxs are released by EHEC in the intestine, translocated across the gut epithelium into the circulation, and transported to microvascular endothelial cells. They presumably damage host cells by inhibiting protein synthesis, stimulating prothrombotic messages, or inducing apoptosis. ${ }^{3}$ Stx has been identified as a critical requirement for the development of hemorrhagic colitis and hemolytic-uremic syndrome, but we hypothesized that in addition, EHEC

${ }^{1}$ Department of Medicine, Section of Digestive Diseases and Nutrition, University of Illinois at Chicago, Chicago, IL, USA and ${ }^{2}$ Jesse Brown VA Medical Center, Chicago, IL, USA

Correspondence: Dr G Hecht, Department of Medicine (MC716), Section of Digestive Diseases and Nutrition, University of Illinois at Chicago, Room 738A, Clinical Sciences Building, 840 S. Wood Street, (MC 716), Chicago, IL 60612-7323, USA.

E-mail: gahecht@uic.edu

Received 22 March 2009; revised 2 January 2010; accepted 26 January 2010 
organisms, in the absence of Stx, exert direct effects on the intestinal epithelium that contribute to diarrhea. Early diarrhea caused by EHEC is nonbloody, and is not likely due to Stx. EHEC infection of cultured intestinal epithelial cells induces $\mathrm{A} / \mathrm{E}$ lesions, alters intestinal epithelial barrier function, modulates ion transport, and stimulates inflammation, suggesting that the mechanisms underlying diarrhea associated with infection by this pathogen are complex and multifactorial. ${ }^{4-6}$

Although several experimental animal models have been developed to elucidate EHEC pathogenesis, ${ }^{7-14}$ the lack of a simple, small murine model has posed a great challenge in understanding EHEC-induced physiological and pathological changes. Moreover, many of the in vivo studies focused on the effect of toxin-producing strains. Nagano et al ${ }^{15}$ have shown that intragastric inoculation of a Stx-producing EHEC O157:H7 strain leads to EHEC adherence to intestinal epithelial cells of ICR mice, resulting in epithelial cell actin accumulation (characteristic of $\mathrm{A} / \mathrm{E}$ lesions). The same group has also reported that fecal shedding of EHEC organisms was observed in ICR mice up to 3 weeks, and that the cecum was a frequent site of adhesion and colonization for these pathogenic bacteria. In addition to ICR mice, C57Bl/6J strains have also been used to study the effects of EHEC infection on ion transport. ${ }^{6}$ Although colonization of EHEC in mice has been shown previously, EHEC-induced pathological changes have not been fully assessed in mouse models.

Therefore, our goal in this study was to define the effects of EHEC, in the absence of Stx, on the intestinal epithelium using a murine model. We chose to use a Stx-negative derivative of EHEC to assess the contribution of virulence factors other than Stx.

\section{MATERIALS AND METHODS Bacterial Strains}

The EHEC O157:H7 strain 85-170, an isogenic Stx-negative derivative, ${ }^{16}$ (generous gift from James Kaper, Center for Vaccine Development, University of Maryland, Baltimore, MD, USA) was used to infect mice in this study. For permeability experiments, a control group of mice was also orally gavaged with a nonpathogenic human fecal isolate HS-4. ${ }^{17}$ For bioluminescence imaging experiments, the EHEC O157:H7 strain 85-170 was transformed with the pCM17 plasmid (generous gift from James Kaper, University of Maryland,) containing the lux CDABE operon driven by the OmpC promoter, which allows constitutive expression of luciferase. ${ }^{18}$ Bacteria were grown overnight at $37^{\circ} \mathrm{C}$ in Luria-Bertani broth, then diluted in serum- and antibiotic-free medium [1:1 (vol/vol)] mixture of Dulbecco's modified Eagle's medium and Ham's F12 medium containing $25 \mathrm{mM}$ glucose, $15 \mathrm{mM}$ HEPES, and $0.5 \%$ [wt/vol mannose], and grown at $37^{\circ} \mathrm{C}$ to mid-log growth phase $\left(\mathrm{OD}_{600 \mathrm{~nm}}=0.4\right)$.

\section{Infection}

Six-week-old C57Bl/6J male mice were obtained from Jackson Laboratory (ME, USA). All animal procedures were approved by the University of Illinois at Chicago Animal Care and Use Committee. Mice were allowed to equilibrate in the Biological Resources Laboratory animal housing facility at the University of Illinois at Chicago for $\sim 7$ days. Two groups of mice were used in this study: antibiotic-free mice and streptomycin-pretreated mice. Antibiotic-free mice were directly gavaged with EHEC after the 7-day equilibration period. The second group of mice was given water containing $5 \mathrm{~g} / \mathrm{l}$ streptomycin for $24 \mathrm{~h}$ on the fifth day of their arrival at the facility. The water supply was then replaced with sterile distilled water for another $24 \mathrm{~h}$ before infection. Both groups of mice were gavaged with $200 \mu \mathrm{l}$ of sterile PBS (control, uninfected), or $2 \times 10^{8}$ Stx-negative EHEC organisms were suspended in $200 \mu \mathrm{l}$ sterile PBS.

\section{Attachment Assays}

To determine the number of EHEC organisms adherent to the intestinal epithelium, at least four EHEC-infected and EHEC-uninfected C57Bl/6J mice were killed at days 1, 3, 5, 8, and 10 after infection. The ileum, cecum, and colon were dissected. Stool contents were removed and tissues were washed with PBS. Tissues were weighed and homogenized in PBS using a Dounce tissue grinder. Homogenized tissues were serially diluted in PBS and plated on MacConkeySorbitol agar (BD Biosciences, NJ, USA) supplemented with $50 \mu \mathrm{g} / \mathrm{l}$ cefixime and $2.5 \mathrm{mg} / \mathrm{l}$ potassium tellurite (SigmaAldrich, MO, USA), which is a selective and differential medium for the detection of sorbitol-nonfermenting E. coli O157:H7. After $18-24 \mathrm{~h}$ of incubation at $37^{\circ} \mathrm{C}$, white colonies were counted and colony-forming units (CFUs) were determined per gram of tissue. White colonies were confirmed as EHEC by PCR using espF-specific primers.

\section{Fecal Shedding of EHEC}

Stool samples obtained from at least four uninfected and infected mice were collected daily for a period of 10 days after infection. Stool samples were weighed and homogenized in PBS by vortexing. Homogenized stool samples were serially diluted and plated on MacConkey-Sorbitol agar supplemented with $50 \mathrm{mg} / \mathrm{l}$ cefixime and $2.5 \mathrm{mg} / \mathrm{l}$ potassium tellurite. After $18-24 \mathrm{~h}$ of incubation at $37^{\circ} \mathrm{C}$, white colonies were counted and CFUs were determined per gram of stool.

\section{Bioluminescent EHEC Infection and Imaging}

The protocol for imaging of bioluminescent EHEC was adapted from a previously described in vivo bioluminescence imaging of Citrobacter rodentium in infected mice. ${ }^{19}$ Bioluminescent EHEC was cultured overnight as described above and orally gavaged into streptomycin pretreated $\mathrm{C} 57 \mathrm{Bl} / 6 \mathrm{~J}$ mice. Three days after infection, mice were killed and entire intestines were excised. The rectum and stomach were tied off and air injected into the lumen of the intestine to activate the 
bioluminescence signal. Bioluminescence was determined by IVIS system (Xenogen Corporation, Hopkinton, MA, USA) and expressed as (photons $\mathrm{s}^{-1} \mathrm{~cm}^{-2} \mathrm{sr}^{-1}$ ). To detect adherent EHEC, cecum and colon tissues were washed extensively with PBS before imaging with IVIS.

\section{Transmission Electron Microscopy}

The distal small intestine and the proximal colonic tissues were retrieved from uninfected and EHEC-infected C57Bl/6J mice and cut into approximately $2-3 \mathrm{~mm}$-long pieces and fixed in $4 \%$ glutaraldehyde with $0.1 \mathrm{M}$ cacodylate buffer. Further routine processing for transmission electron microscopy (TEM) was performed in the Electron Microscopy Facility at the University of Illinois at Chicago.

\section{Histological Staining}

Proximal colonic tissues retrieved from uninfected and EHEC-infected C57Bl/6J mice were cut into approximately $2-3 \mathrm{~mm}$-long pieces and fixed in $10 \%$ neutral buffered formalin. Further routine processing for hematoxylin and eosin staining was performed in the Research Resource Center at the University of Illinois at Chicago.

\section{Electrophysiology}

At days 1, 3, 5, 8, and 10 after infection, mice were killed by $\mathrm{CO}_{2}$ asphyxiation and intestinal tissues were resected. Tissue sections of the proximal colon were mounted in an Üssing chamber for measurement of transmucosal electrical resistance (TER), a previously described indicator of barrier function. ${ }^{20}$ Full thickness, unstripped mucosa was bathed on both mucosal and serosal surfaces with $5 \mathrm{ml}$ of oxygenated $\left(95 \% \mathrm{O}_{2} / \mathrm{CO}_{2}\right)$ Ringer's solution containing $109.8 \mathrm{mM} \mathrm{NaCl}, 5.3 \mathrm{mM} \mathrm{KCl}$, $1.2 \mathrm{mM} \mathrm{CaCl}_{2}, 1.2 \mathrm{mM} \mathrm{MgCl}, 25 \mathrm{mM} \mathrm{NaHCO}, 2.4 \mathrm{mM}$ $\mathrm{Na}_{2} \mathrm{HPO}_{4}$, and $0.4 \mathrm{mM} \mathrm{NaH} \mathrm{PO}_{4}$. To maintain tissue viability, $5 \mathrm{mM}$ glucose was added on the mucosal side of the tissue and $5 \mathrm{mM}$ mannitol was added on the serosal side of the tissue.

\section{Permeability Measurements}

At day 8 after infection, mice were killed by $\mathrm{CO}_{2}$ asphyxiation and intestinal tissues were resected. Upon equilibration of the tissue and measurement of electrical parameters, $4-\mathrm{kDa}$ FITC-dextran was added to the mucosal side to achieve a final concentration of $0.01 \mathrm{mM}$. Permeability (flux) was determined after removal of the medium from the serosal compartment at the end of a 90-min experimental period. The medium was then assessed for fluorescence using a microplate fluorescence reader (FL-500, BIO-TEK, VT, USA) at an excitation wavelength of $485 \mathrm{~nm}$ and an emission wavelength of $530 \mathrm{~nm}$.

\section{Immunofluorescence Microscopy}

Tissue samples of the proximal colon from all mice killed for Üssing chamber analysis were snap frozen in optimal cutting temperature embedding medium (Tissue-Tek O.C.T. compound, Sakura Finetek USA, CA, USA) and stored at $-80^{\circ} \mathrm{C}$.
For immunostaining, $5 \mu \mathrm{m}$ frozen sections were fixed with $1 \%$ paraformaldehyde in PBS for $10 \mathrm{~min}$ at room temperature. After washing with PBS, permeabilization with $0.5 \%$ NP- 40 , and blocking of nonspecific binding sites with 5\% normal goat serum (NGS), tissues were incubated with monoclonal mouse anti-occludin, rabbit anti-ZO-1, rabbit anti-claudin-2, or rabbit anti-claudin-3 (at $0.5 \mu \mathrm{g} / \mathrm{ml}$, Invitrogen, CA, USA) in PBS with $1 \%$ NGS for $90 \mathrm{~min}$ at room temperature. After washing, sections were incubated with $8 \mu \mathrm{g} / \mathrm{ml}$ Alexa 594-conjugated goat anti-mouse IgG or $8 \mu \mathrm{g} / \mathrm{ml}$ goat anti-rabbit IgG antisera, 5 Units/ml Alexa 488-conjugated phalloidin, and Hoechst 33342 (Invitrogen) for $60 \mathrm{~min}$. Sections were then washed and mounted under coverslips using ProLong Gold antifade reagent (Invitrogen). Sections were imaged using a Leica Dm4000B epifluorescence microscope and Slide Book 4.2 software (Intelligent Imaging Innovations, CO, USA).

\section{Quantitative Real-Time PCR}

Four colonic samples for each group of uninfected and infected mice at days $1,3,5,8$, and 10 after infection were analyzed for quantitative real-time PCR (qRT-PCR) using mRNA-specific primers for Ocln, Cldn2, Cldn3, and Gapdh. Tissue samples previously preserved in OCT and stored at $-80^{\circ} \mathrm{C}$ were microdissected. In all, 9 of $10-\mu \mathrm{m}$ thick sections were collected per sample and total RNA was extracted using RNeasy microkit (Qiagen, CA, USA). Total mRNA was prepared using First-Strand cDNA Synthesis Kit (Fermentas, MD, USA). cDNA targets were cloned in pCR4-TOPO vector (Invitrogen). Known amounts of serially diluted recombinant plasmids were prepared and served as standards for qRTPCR. Test samples and plasmid standards were used as templates for qRT-PCR using mRNA-specific primers for Ocln, Cldn2, Cldn3, and Gapdh and Fast Sybr Green PCR Master Mix (Applied Biosystems, TX, USA). qRT-PCR reactions were carried out at $50^{\circ} \mathrm{C}$ for $2 \mathrm{~min}, 95^{\circ} \mathrm{C}$ for $10 \mathrm{~min}$, followed by 40 cycles of $95^{\circ} \mathrm{C}$ for $15 \mathrm{~s}$ and $60^{\circ} \mathrm{C}$ for $1 \mathrm{~min}$, and a dissociation step at $95^{\circ} \mathrm{C}$ for $15 \mathrm{~s}, 60^{\circ} \mathrm{C}$ for $15 \mathrm{~s}$, and $95^{\circ} \mathrm{C}$ for $15 \mathrm{~s}$ using an ABI 7900HT Sequence Detection System (Applied Biosystems). Sequences of primers used are as follows: Ocln forward: $5^{\prime}$-AGAGGCTATGGGACAGGGCTC TTTGG-3', Ocln reverse: $5^{\prime}$-CCAACAGGAAGCCTTTGG CTGCTCTTGG-3'; Cldn2 forward: $5^{\prime}$-CCTCGCTGGCTTG TATTATCTCTG-3', Cldn2 reverse: $5^{\prime}$-GAGTAGAAGTCCCG AAGGATG-3'; Cldn3 forward: 5'-CCGGTTCAAGTCCAG CAGCCATGTC-3', Cldn3 reverse: 5'- GCTCTGCACCACGC AGTTCATCC-3'; Gapdh forward: $5^{\prime}$ - GAAGGGCTCATGA CCACAGT- $3^{\prime}$ and Gapdh reverse: $5^{\prime}$-GGATGCAGGGATG ATGTTCT- $3^{\prime}$. Absolute mRNA copies of the targets were determined per absolute mRNA copies of Gapdh for each sample.

\section{Statistical Analysis}

All data are reported as mean and s.e.m. Data comparisons were made with Student's $t$-test. Differences were considered significant when the $P$-value was $\leq 0.05$. 


\section{RESULTS}

\section{E. coli 0157:H7 Colonization of Mouse Intestines}

We tested the ability of E. coli O157:H7 to colonize and adhere to the intestines of $\mathrm{C} 57 \mathrm{Bl} / 6 \mathrm{~J}$ mice after oral gavage of $2 \times 10^{8}$ bacteria with or without streptomycin pretreatment. EHEC infection of antibiotic-free mice resulted in the colonization of the ileum, cecum, and colon (Figure 1a-c). A
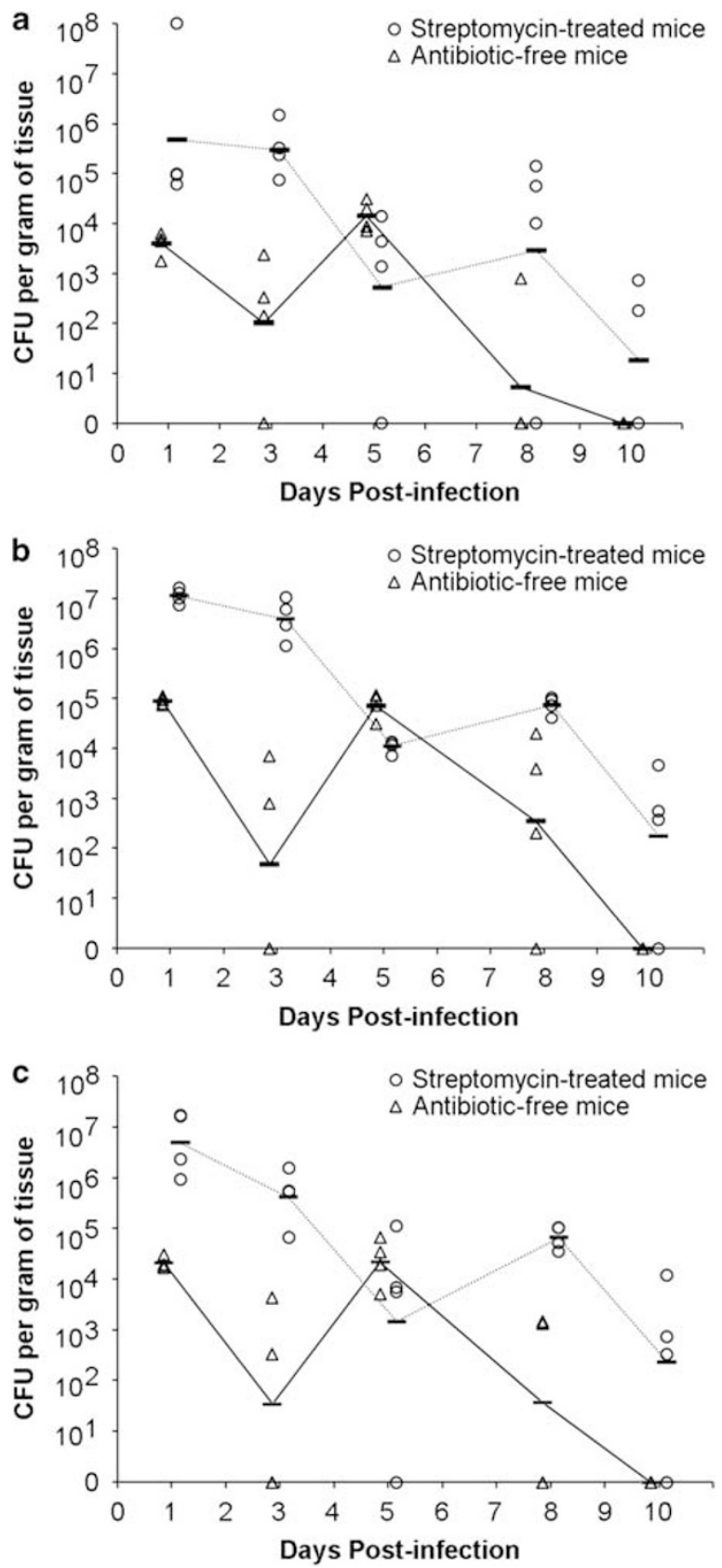

Figure 1 Localization of $E$. coli 0157:H7 in mouse intestines. The presence of $E$. coli $0157: \mathrm{H7}$ in the ileum (a), cecum (b), and proximal colon (c) of infected $\mathrm{C} 57 \mathrm{BI} / 6 \mathrm{~J}$ mice was determined at 1, 3, 5, 8, and 10 days after infection. Group geometric mean of CFU per gram of tissue is shown for infected mice that did not receive antibiotics (triangles) and for mice treated with streptomycin before EHEC infection (circles). significant (2.2 to $3 \log )$ growth expansion of EHEC attached to the ileum, cecum, and colon was observed at 5 days after infection in the absence of antibiotics. By 10 days after infection, EHEC was no longer detected in the intestinal tissue samples of antibiotic-free mice. Greater amounts of tissueassociated EHEC were observed at days 1 and 3 in mice treated with streptomycin before infection. In streptomycin pretreated mice, growth expansion of EHEC associated with the ileum, cecum, and colon also occurred, but at 8 days after infection. In contrast to the antibiotic-free mouse model of infection, EHEC remained detectable ( $>2$ logs per gram of tissue) in the tissue samples even at 10 days after infection. In both models, EHEC colonizes the cecum and colon more efficiently than the ileum.

Bioluminescence imaging of EHEC in the intestinal tissues of infected mice was used to confirm that the bacteria localize and adhere to the cecum and colon (Figure 2). Although bioluminescence imaging technique offers easier localization of bacteria in host tissues, it is not as sensitive as culturing tissues or stool from infected animals. Bioluminescence was not able to detect EHEC in tissue sections, such as the ileum, where lower amounts $\left(<10^{5} \mathrm{CFU}\right.$ per gram of tissue) of colonizing bacteria are found. To determine whether EHEC intimately adhered to the intestinal epithelium, the intestine of infected animals was opened and washed multiple times in a vigorous manner to remove nonadherent organisms and reimaged. Significant bioluminescent signal was still detected primarily in the cecum and proximal colon, indicating that EHEC tightly adheres to the intestinal epithelium (Figure 2b).

The amount of EHEC shed in the feces was also monitored daily for 10 days. Consistently greater numbers of EHEC were cultured from the feces of mice pretreated with streptomycin, as compared with those that received no antibiotics (Figure 3). We also observed small $(0.5-1.5 \mathrm{log}$ ), but significant, growth expansion of EHEC in the stool sample at 8 days after infection in both infection models. Despite the fact that EHEC was not recovered from intestinal tissues at day 10 in mice that had not received antibiotics, $>10^{3}$ organisms were cultured per gram of stool.

\section{Alteration of Intestinal Microvilli after E. coli 0157:H7 Infection}

To evaluate the effect of EHEC infection on mouse intestinal epithelial cells, TEM was performed on small and large intestinal segments obtained from uninfected and infected antibiotic-free mice at 1 and 5 days after infection, respectively (Figure $4 \mathrm{a}$ and $\mathrm{b}$ ). Although the small intestine and colon of uninfected mice displayed normal microvillous architecture, localized effacement of the microvilli was detected in EHEC-infected mice predominantly in the colon at both 1 and 5 days after infection. Effacement appeared more extensive and remarkable at 1 day after infection. The microvillous architecture of the ileum of EHEC-infected mice appeared well preserved. Although effacement was evident in 

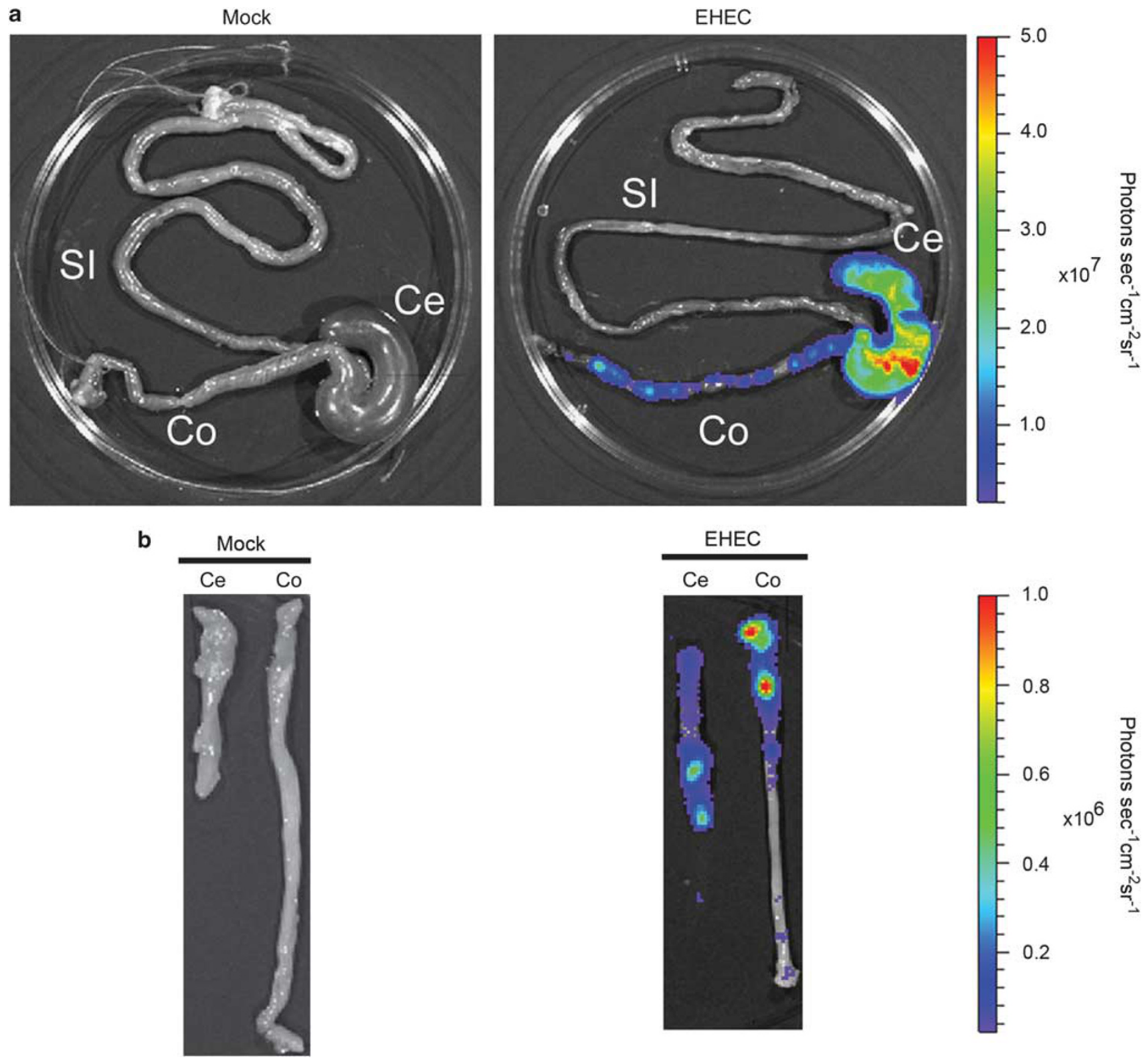

Figure 2 Imaging of intestinal tissues of streptomycin-pretreated mice infected with bioluminescent EHEC. (a) The entire intestine (si, small intestine; ce, cecum; co, colon) was excised from mice orally infected with bioluminescent EHEC for 3 days. A pseudocolor image depicting bioluminescence intensity (red, more intense; blue, less intense) was generated using Living Image Software (Xenogen Corporation) and superimposed onto the photographic image. The color bar indicates relative signal intensity (photons $\mathrm{s}^{-1} \mathrm{~cm}^{-2} \mathrm{sr}^{-1}$ ). (b) Thereafter, the cecum and colon were opened longitudinally and washed with PBS before imaging with IVIS. Data representative of EHEC- $(n=9)$ and mock-infected $(n=5)$ mice from two separate experiments.

the colon, intimately attached bacteria and the well-characterized $\mathrm{A} / \mathrm{E}$ lesions with pedestals were not readily found by TEM. However, the distortion and effacement of the microvilli observed in the colon of EHEC-infected mice is consistent with changes induced by enteropathogenic E. coli. ${ }^{20}$ We also analyzed by TEM the effect of EHEC on colonic epithelial cells of mice pretreated with streptomycin (Figure 5). Distortion and localized effacement of the microvilli in the colon were easily identified at $3,5,8$, and 10 days after infection. In the colon of infected mice pretreated with streptomycin, microvillous effacement was most extensive at 3 days after infection, but was still detectable at day 10 after infection.

\section{Mild Colonic Inflammation of Mice Infected with EHEC 0157:H7}

To further assess histological changes due to EHEC infection, colonic segments from uninfected and infected mice pretreated with streptomycin were stained with hematoxylin and eosin. A modest increase in the number of polymorpho- 


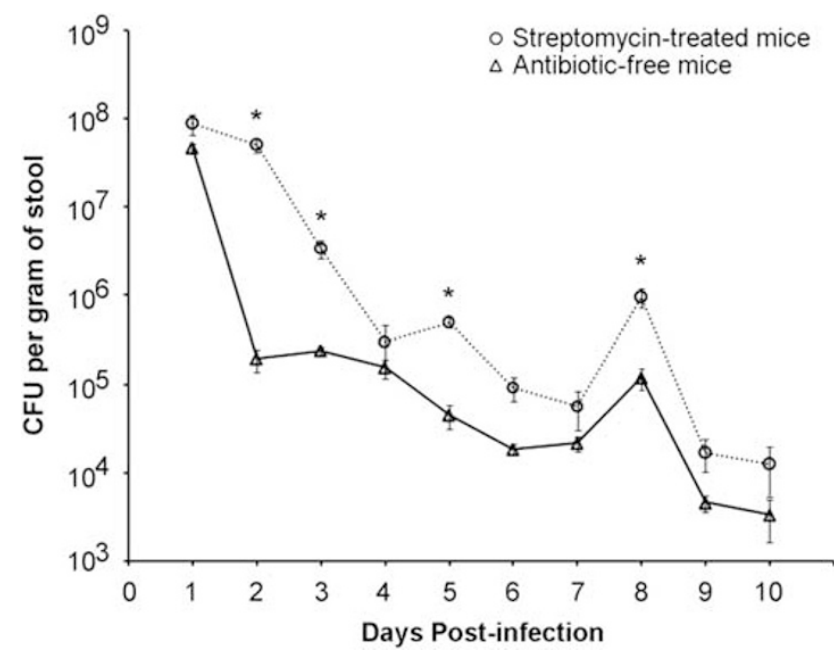

Figure 3 Fecal shedding of $E$. coli $0157: \mathrm{H} 7$ in mice after inoculation with the pathogen. $C 57 \mathrm{BI} / 6 \mathrm{~J}$ mice were orally gavaged with $2 \times 10^{8}$ of $E$. coli 0157:H7 and their feces were monitored for the presence of bacteria over a period of 10 days. Group geometric mean of CFU per gram of feces is shown for infected mice that did not receive antibiotics (triangles) and for mice treated with streptomycin before EHEC infection (circles). ${ }^{*}$ Indicates $P$-value $<0.05$ when daily fecal shedding of EHEC in antibiotic-free mice and streptomycin-pretreated mice are compared.

nuclear leukocytes was found at the lamina propria of mouse colonic tissues at day 3 after infection as compared with uninfected control (Figure 6), but not at days 1, 5, 8, and 10 after infection (data not shown).

\section{Disruption of Intestinal Barrier Function in Mice Infected with EHEC 0157:H7}

To evaluate the effect of EHEC infection on intestinal epithelial cell barrier function, colonic segments from uninfected and infected mice were mounted in Üssing chambers and electrophysiological parameters were measured. In the antibiotic-free mouse model of EHEC infection, electrical resistance of the colon of infected mice was reduced significantly at days 3 and 5 after infection when compared with values obtained from tissues of uninfected control mice, suggesting disruption of tight junctions (TJs) (Figure 7a). In the colon of infected mice pretreated with streptomycin, resistance values decreased progressively over time, with the maximum reduction detected at 8 days after infection (Figure $7 b$ ). Disruption of intestinal epithelial barrier function was also evaluated by measuring the flux of $4-\mathrm{kDa}$ FITC-dextran across colonic segments. Colonic samples were obtained from streptomycin-pretreated mice at day 8 after infection, wherein maximum TER reduction was previously observed. A significant increase in mucosal permeability of colonic samples to 4-kDa FITC-dextran was detected in the colon of EHEC-infected mice (Figure 8a). Colonic samples from a control group of mice orally gavaged with a nonpathogenic human fecal isolate HS-4 had permeability and TER mea- surements similar to values from uninfected control mice (Figure $8 \mathrm{a}$ and $\mathrm{b}$ ).

\section{EHEC Infection Modifies Occludin, Claudin-2, and Claudin-3 Localization in the Colon, but not ZO-1}

To determine whether the physiological changes in the TJ barrier were accompanied by alterations in the distribution of TJ proteins, the colonic tissues of EHEC-infected and EHECuninfected mice were analyzed using immunofluorescence staining of ZO-1, occludin, claudin-2, and claudin-3. At 1 day after infection, neither the ileum nor the colon of infected mice showed redistribution of TJ proteins (data not shown) correlating with normal electrical resistance measurements. No difference in the distribution or intensity of staining of the intracellular scaffolding protein ZO-1 was seen in the colons of uninfected mice compared with those infected with EHEC (Figure 9) over the course of infection. The transmembrane $\mathrm{TJ}$ protein occludin was also examined in the colonic tissues of EHEC-infected and EHEC-uninfected mice. Occludin was redistributed, specifically internalized, in colonic epithelial cells from animals infected with EHEC (Figure 10), similar to changes reported in mice infected with enteropathogenic E. coli. ${ }^{21}$ Immunofluorescent staining for claudin-3 revealed staining primarily localized to the lateral membranes, but some intracellular localization was also observed. At 3 days after infection, claudin-3 staining was clearly diminished (Figure 11). The most interesting results regarded changes in claudin-2. At 1 day after infection, a slight increase in the amount of claudin-2 within the cytoplasm was noted. However, a more significant and progressive increase in claudin-2 expression, both at the TJs and within the cytoplasm, was seen at days 3, 5, 8, and 10 after infection (Figure 12).

\section{EHEC Regulates mRNA Transcription of Ocln, Cldn2, and Cldn3}

To determine whether EHEC-induced perturbation of intestinal epithelial barrier function was associated with altered transcription of genes encoding TJ proteins, we performed qRT-PCR on colonic samples using specific primers for $\mathrm{Ocln}$, Cldn2, Cldn3, and Gapdh. Total RNA was extracted from microdissected colonic samples of uninfected control and EHEC-infected mice pretreated with streptomycin. cDNA was synthesized from the total RNA extract, and the product served as template for qRT-PCR. Absolute mRNA copies of Ocln, Cldn2, and Cldn3 per mRNA copies of Gapdh were determined for each sample (Figure 13). Ocln transcription was altered by EHEC infection with a 1- to 1.4-fold decrease occurring at days 3,5 , and 8 after infection. By 10 days after infection, there was a significant 1.5 -fold increase in the $O c l n$ mRNA transcript levels in the colon of EHEC-infected mice, as compared with uninfected control. EHEC also altered the transcription of Cldn3. At 1 day after infection, a significant two-fold increase in transcription occurred. However, thereafter, a progressive decrease in Cldn3 transcription, 
reaching its lowest level of a two-fold decrease at 8 days after infection, was seen. By day 10, Cldn3 mRNA transcripts increased to levels similar to those of uninfected controls. Interestingly, a 1.5- to 2-fold increase in the mRNA transcription of Cldn2 in the colon of EHEC-infected mice compared with uninfected control mice was demonstrated. The maximum increase in Cldn2 transcription occurred at 3 days after infection but remained above baseline for up to 10 days. The increased Cldn2 transcription correlates with the increased claudin-2 expression in colonic samples as determined by immunofluorescence staining.

\section{DISCUSSION}

EHEC can cause a wide spectrum of clinical outcomes ranging from nonbloody diarrhea to hemorrhagic colitis to lifethreatening hemolytic-uremic syndrome. Stx is implicated in the development of hemorrhagic colitis and hemolyticuremic syndrome. However, early symptoms of EHEC infection such as nonbloody diarrhea ${ }^{22}$ are likely to be Stx independent. Although previous in vivo models have been used to investigate the effects of EHEC infection, ${ }^{7,12}$ most studies used germ-free or antibiotic-treated mice to optimize colonization of Stx-producing EHEC. ${ }^{13,23,24}$ We were

a

DAY 1
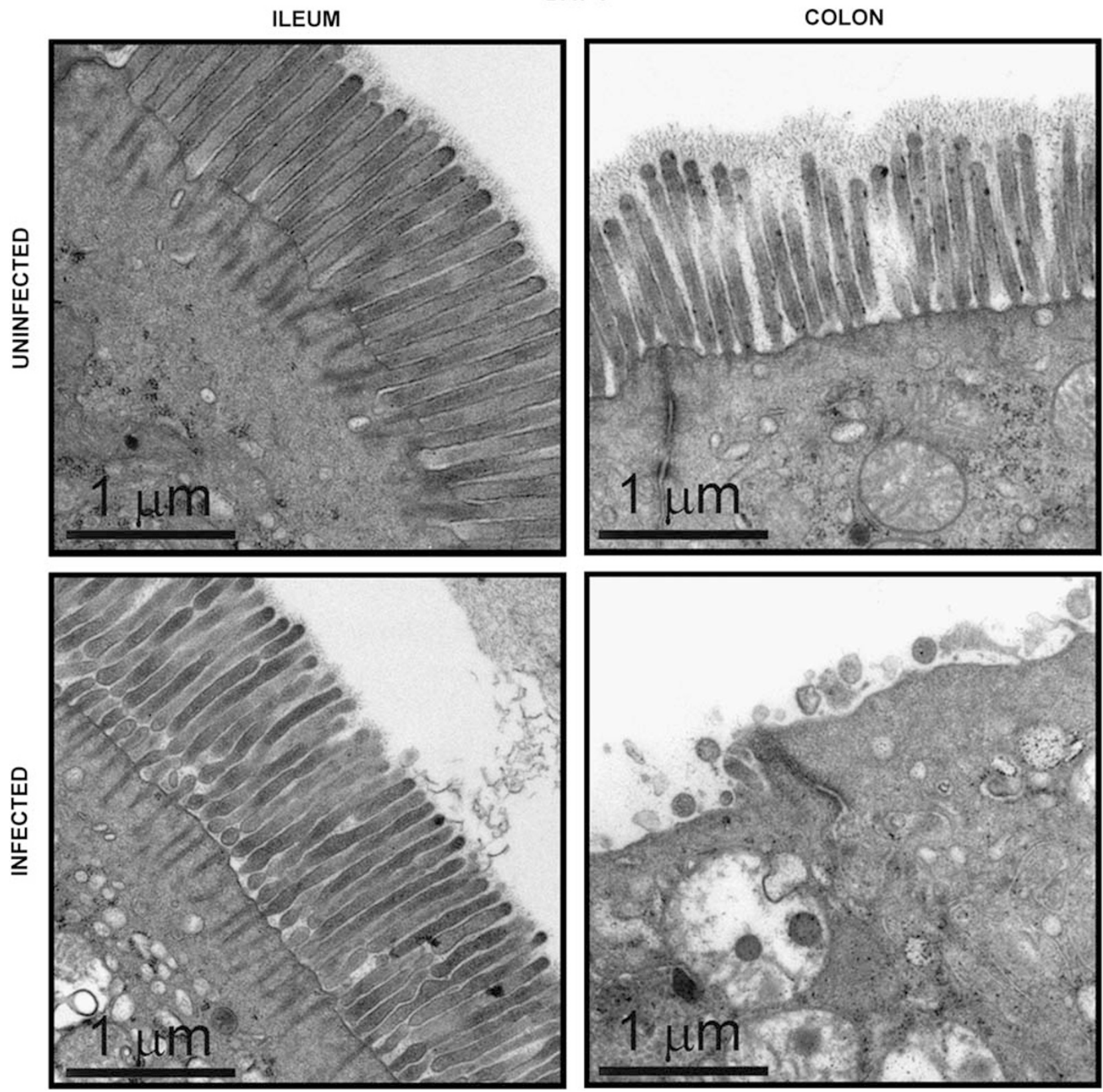

Figure 4 Electron micrograph images of the ileum and colon of uninfected and EHEC-infected antibiotic-free C57BI/6J mice at day 1 (a) and day 5 (b) after infection. Scale bar $=1 \mu \mathrm{m}$. 
b
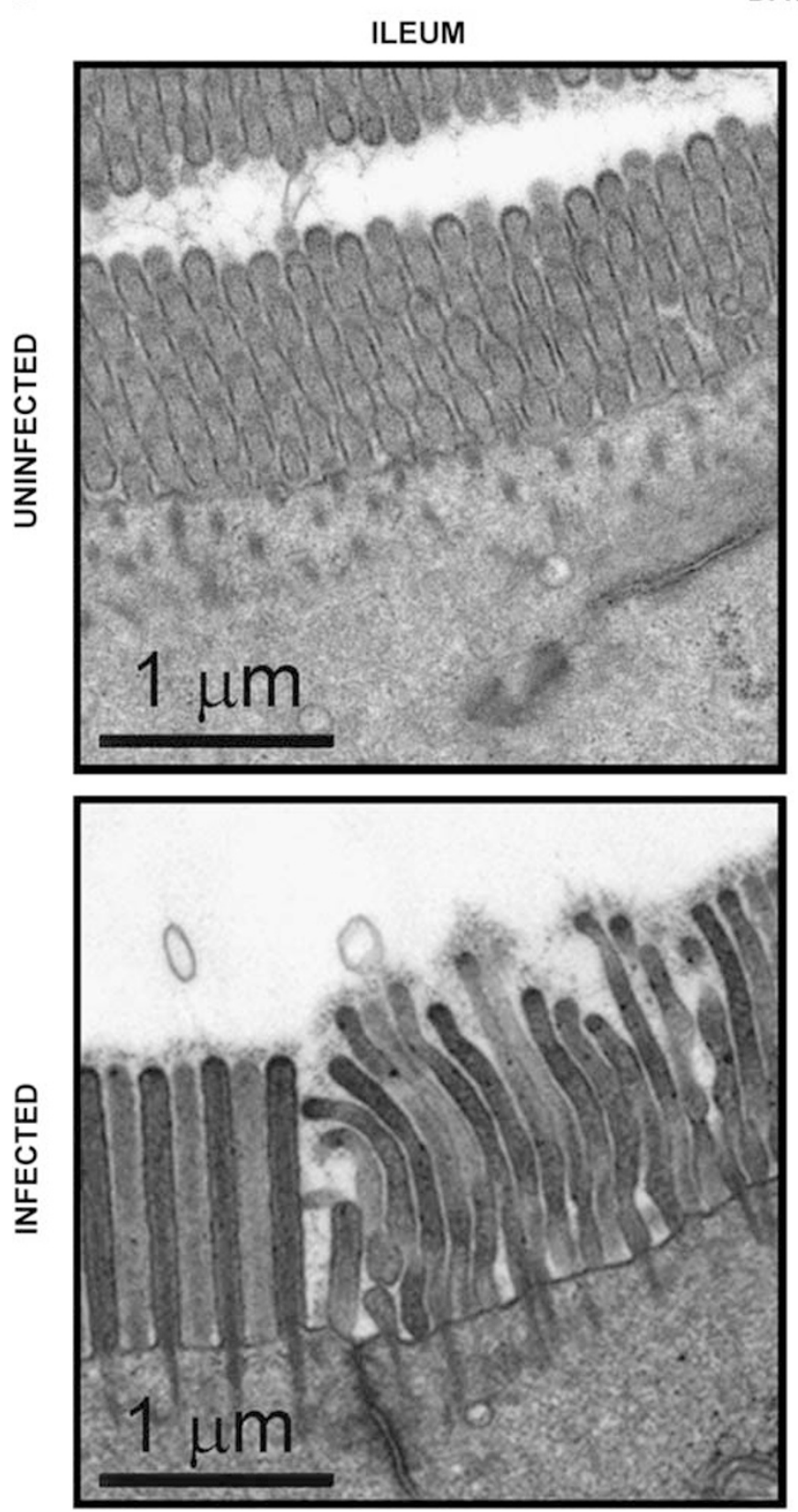

DAY 5
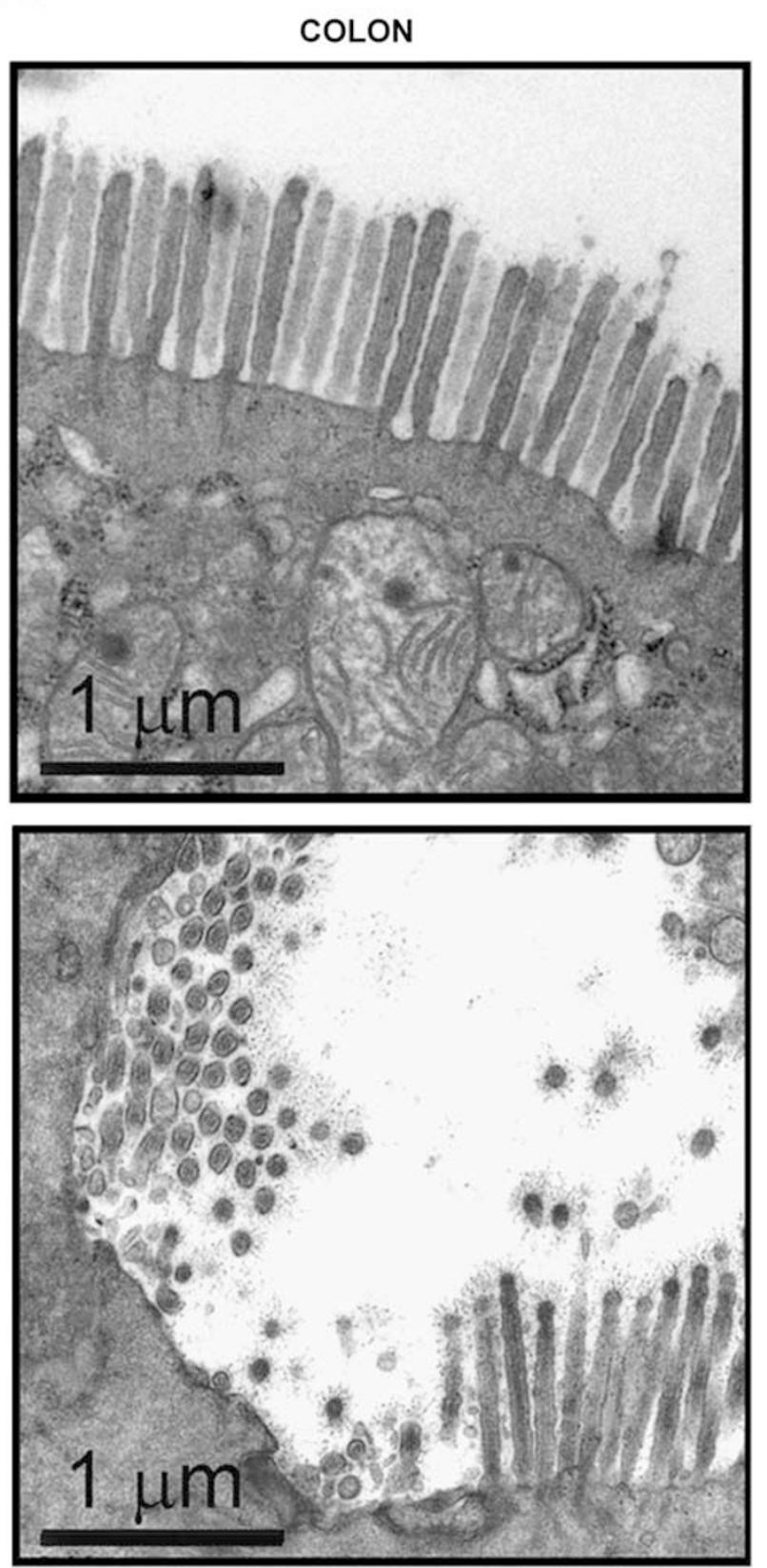

Figure 4 Continued.

interested in examining the effects of EHEC organisms in the absence of Stx in a mouse model. We showed in this study that Stx-negative EHEC attach and colonize the intestinal tissue of $\mathrm{C} 57 \mathrm{Bl} / 6 \mathrm{~J}$ mice, resulting in structural and pathophysiological changes in the epithelium.

Previous mouse studies that used Stx-negative EHEC strains have suggested that the bacteria do not effectively colonize host intestines. Mundy et al ${ }^{25}$ compared the colonization potential of EHEC O157:H7 (strain Sakai), EPEC (strain E2348/69), C. rodentium (strain ICC169), and commensal E. coli (strain Nissle 1917) in C3H/Hej mice. For the first 2 days after infection, all strains were shed in stools at comparable numbers, but at day 3 after infection, fecal shedding of C. rodentium increased by $1.5-\log$ and $\sim 10^{8}$ bacteria per gram stool was detected on days 3,6 , and 8 . In contrast, no growth expansion phase of EHEC, EPEC, and commensal E. coli was detected in the stool and only approximately $10^{3}-10^{4}$ bacteria per gram stool were found at days 3, 6, and 8. Significantly lower levels of EHEC, EPEC, and commensal E. coli were recovered from the intestinal tissues at day 8 after infection, as compared with the levels of tissue-associated C. rodentium. They concluded that the 
EHEC and EPEC strains associated with the mouse intestine were similar to the commensal $E$. coli strain.

For infected $\mathrm{C} 57 \mathrm{Bl} / 6 \mathrm{~J}$ mice that did not receive antibiotics, the amounts of EHEC shed in the stool and associated with the different intestinal tissues at day 8 after infection were comparable with those reported by Mundy et al. However, in contrast to their results, we found growth expansions of EHEC in stool samples at day 8 after infection and of tissue- associated EHEC at day 5 after infection. For EHEC to colonize the host intestinal epithelium, the bacteria must first evade the host's innate immune system. The delayed growth of the colonizing EHEC in our model may be attributed to the host's immune response, as well as to the adaptation of bacteria to its new environment. For antibiotic-treated animals, the growth expansion of colonizing EHEC was further delayed to day 8 after infection. As the EHEC strain used in

\section{UNINFECTED}

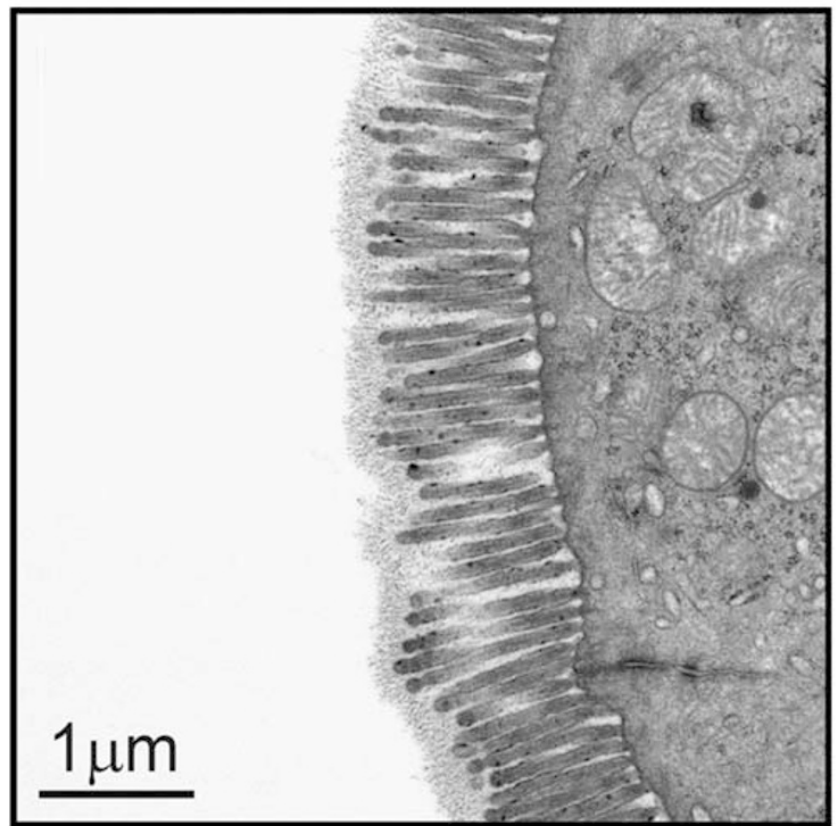

\section{DAY 1}

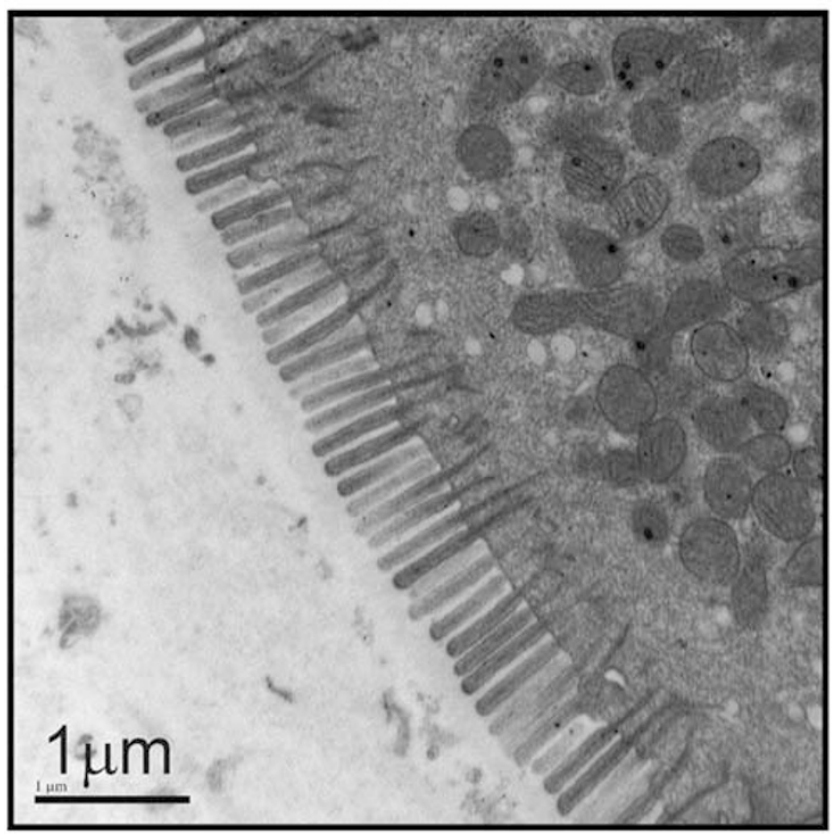

DAY 5

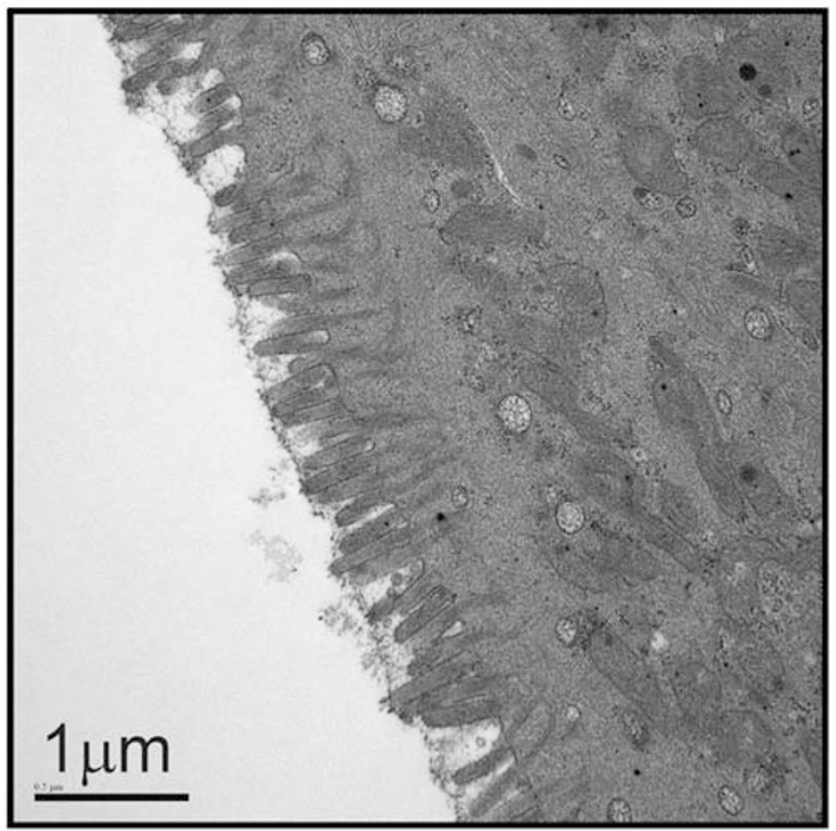

DAY 8

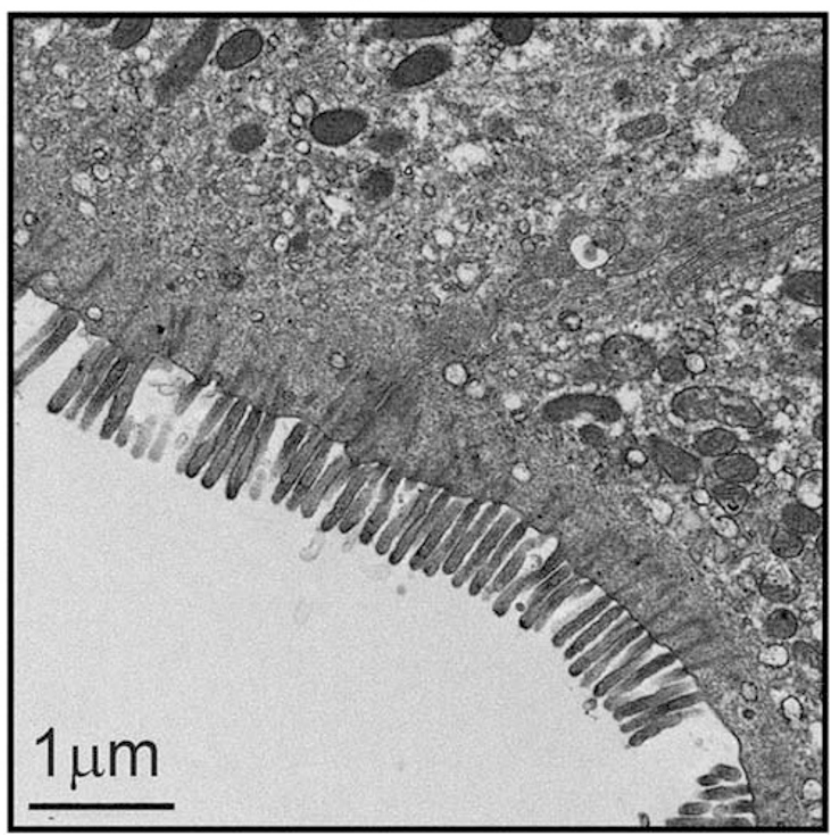

Figure 5 Electron micrograph images of the colonic tissues from uninfected and EHEC-infected C57BI/6J mice pretreated with streptomycin at days 1, 3, 5 , 8 , and 10 after infection. Scale bar $=1 \mu \mathrm{m}$. 


\section{DAY 3}

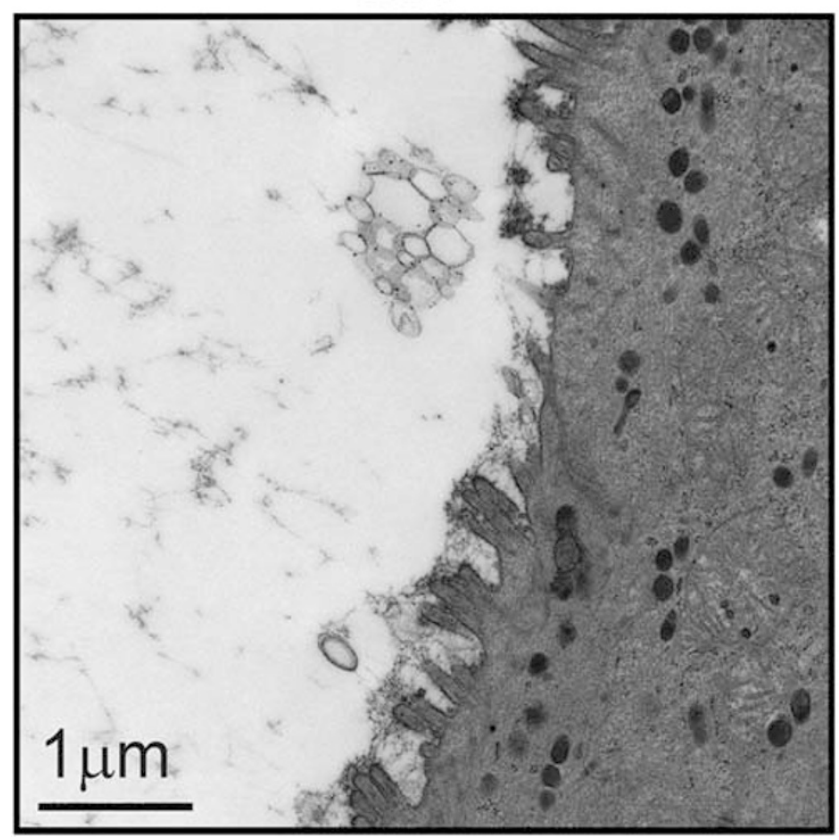

DAY 10

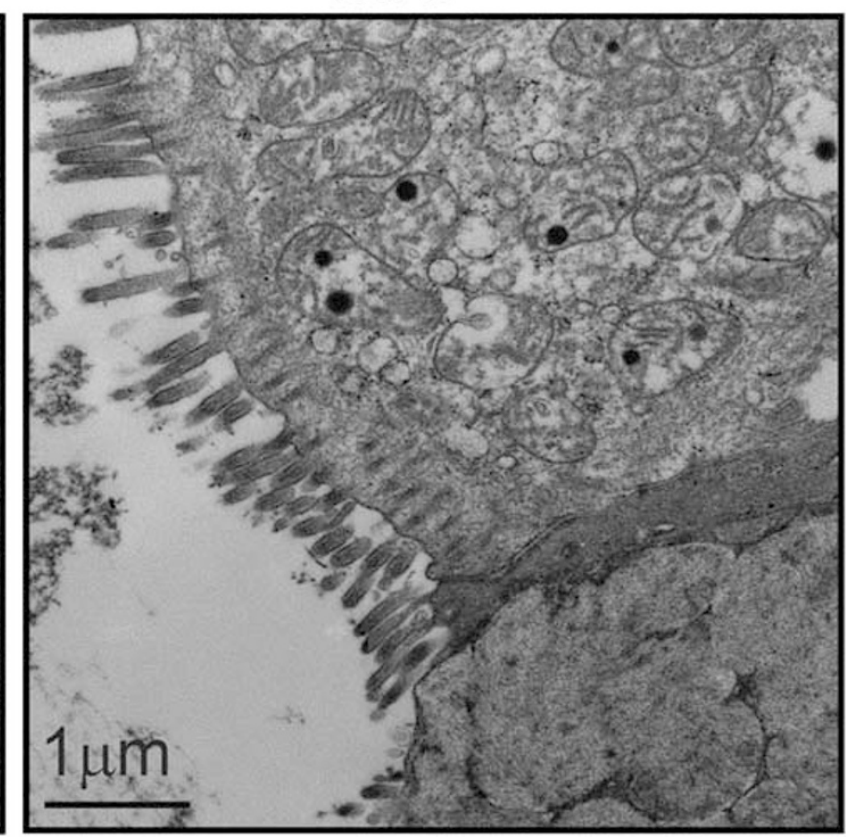

Figure 5 Continued.

\section{UNINFECTED}

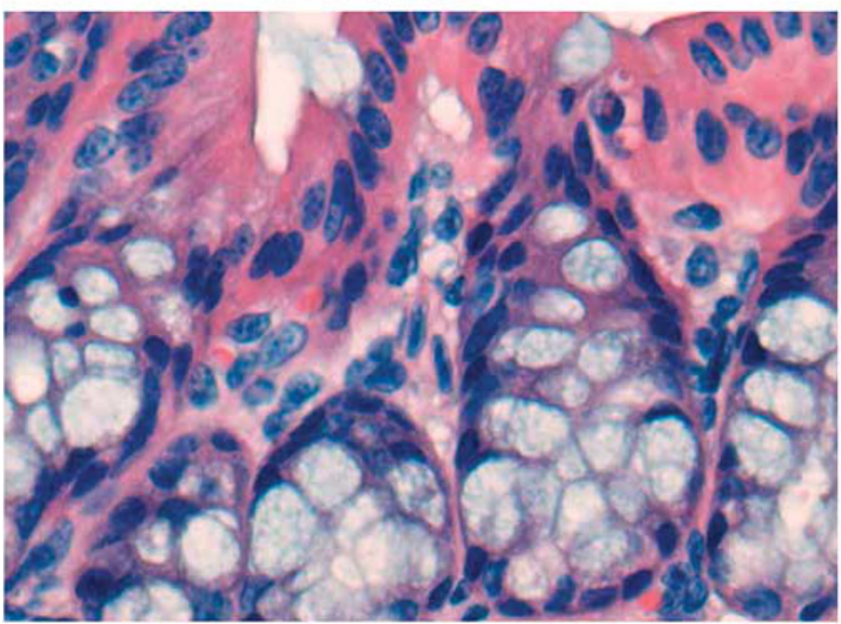

\section{INFECTED}

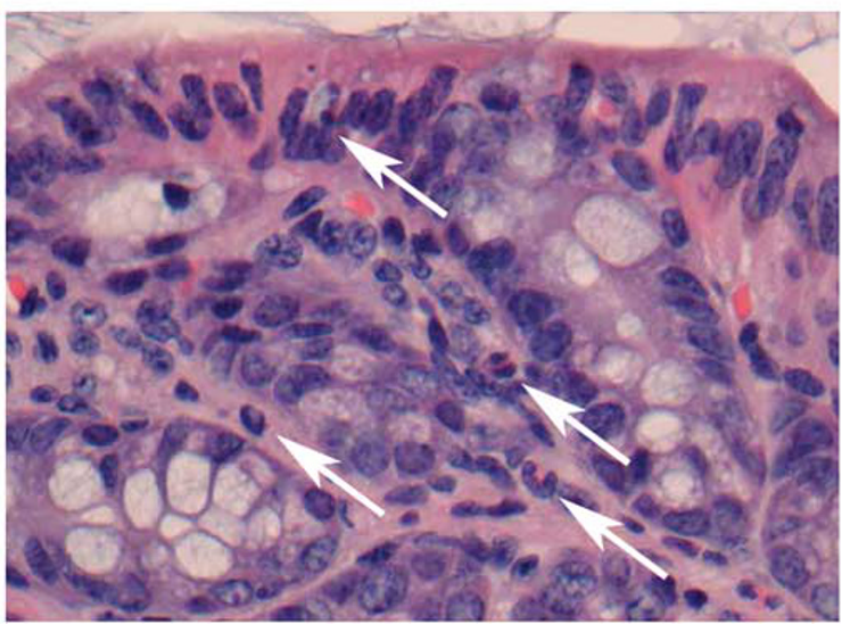

Figure 6 Hematoxylin and eosin staining of the colonic tissues from uninfected and EHEC-infected C57BI/6J mice pretreated with streptomycin at day 3 after infection. Arrows point to lamina propria polymorphonuclear leukocytes.

this study is sensitive to streptomycin, the shift in bacterial growth expansion may be due to residual effects of the antibiotics.

Although EHEC colonize the intestine of C57Bl/6J mice that are not treated with antibiotics, improved bacterial colonization was attained by pretreatment with streptomycin. Streptomycin disrupts the normal microflora of mouse intestines and enhances colonization of nonindigenous bacteria. Previously established mouse models using streptomycin before and during infection have been shown to increase colonization of other pathogens, such as Salmonella typhimurium, Pseudomonas aeruginosa, and Aeromonas isolates. ${ }^{26-28}$ Several mechanisms explaining enhanced colonization of nonindigenous bacteria in streptomycin-treated animals include: (1) decreased competition between resident and nonindigenous bacteria for nutrients and attachment sites, and (2) environmental changes in the gut favoring colonization and growth of pathogens, such as increase in $\mathrm{pH}$ and decrease in short-chain volatile fatty acids. ${ }^{27,29,30}$ One limitation in the use of streptomycin in in vivo models of infection is that the pathogen being studied should be resistant to the antibiotics. In our study, the EHEC O157:H7 strain used was 

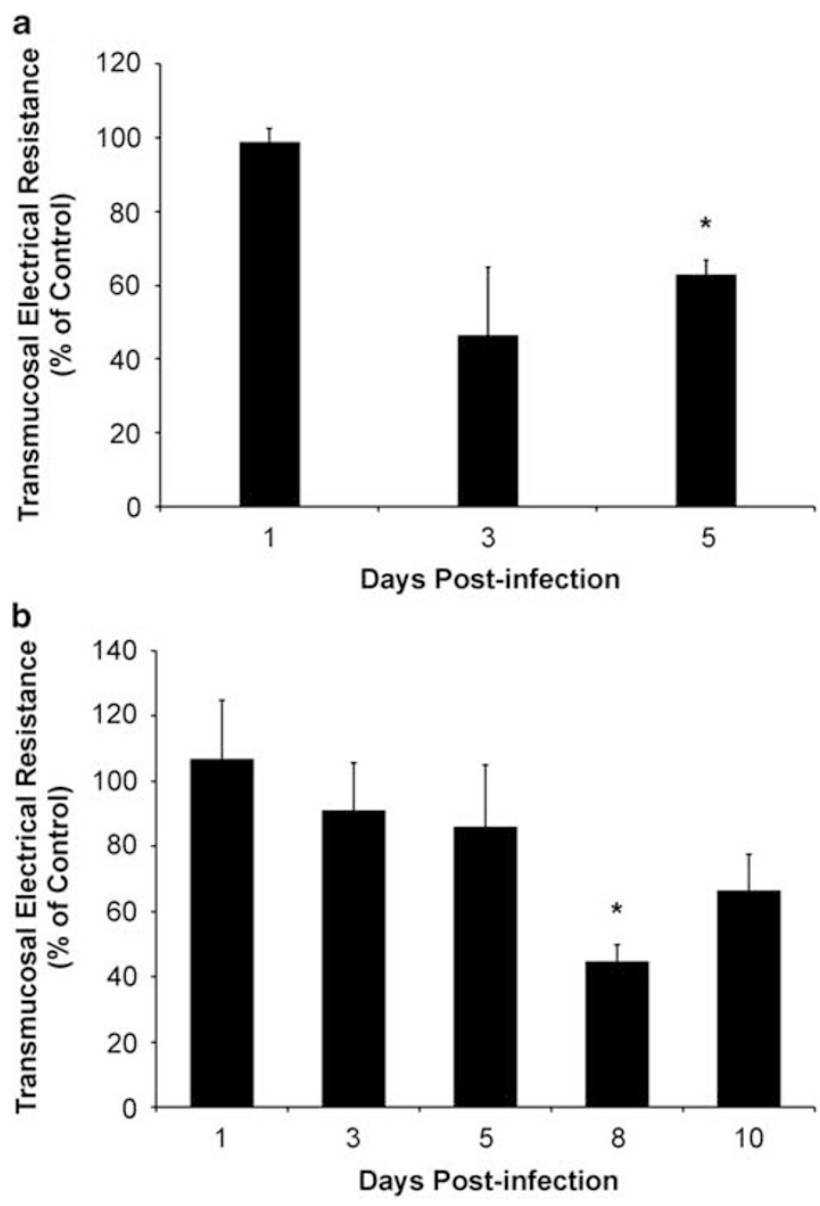

Figure 7 Transmucosal electrical resistance (TER) of the colonic tissues from antibiotic-free C57BI/6J mice infected with EHEC (a) and mice pretreated with streptomycin (b). Segments of the colonic tissues were mounted in Üssing chambers and TER values were determined. Group geometric means of TER of colons of infected mice are shown as percentage of uninfected control mice. ${ }^{*}$ Indicates $P$-value $<0.05$ when daily TER values of the colonic tissues from infected mice are compared with uninfected control mice.
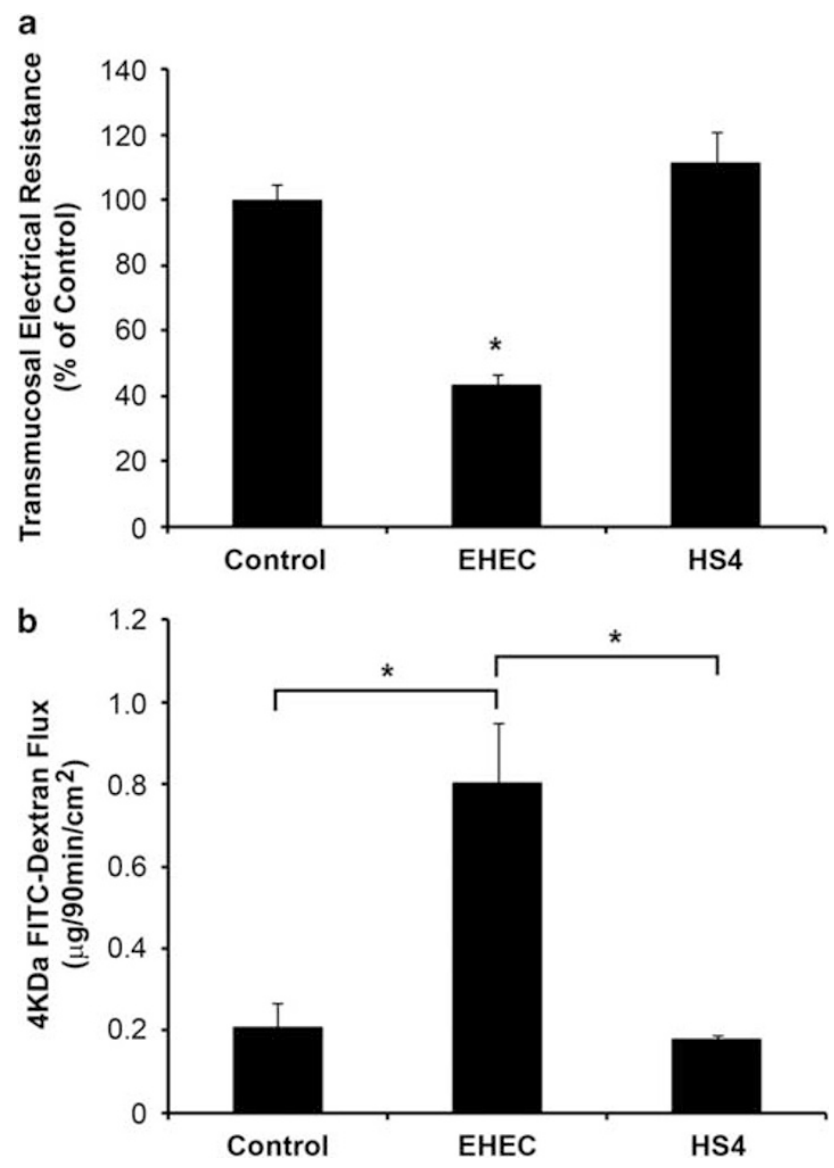

Figure 8 Mucosal permeability to 4-kDa FITC-dextran of the colonic tissues from infected mice pretreated with streptomycin at day 8 after infection. (a) Transmucosal electrical resistance of the colonic tissues from uninfected, EHEC-, and HS-4-infected mice. (b) Flux of 4-kDa FITC-dextran across mouse colonic tissues from uninfected, EHEC-, and HS-4 infected mice determined at the end of a 90-min experimental period. ${ }^{*}$ Indicates $P$-value $<0.01$.
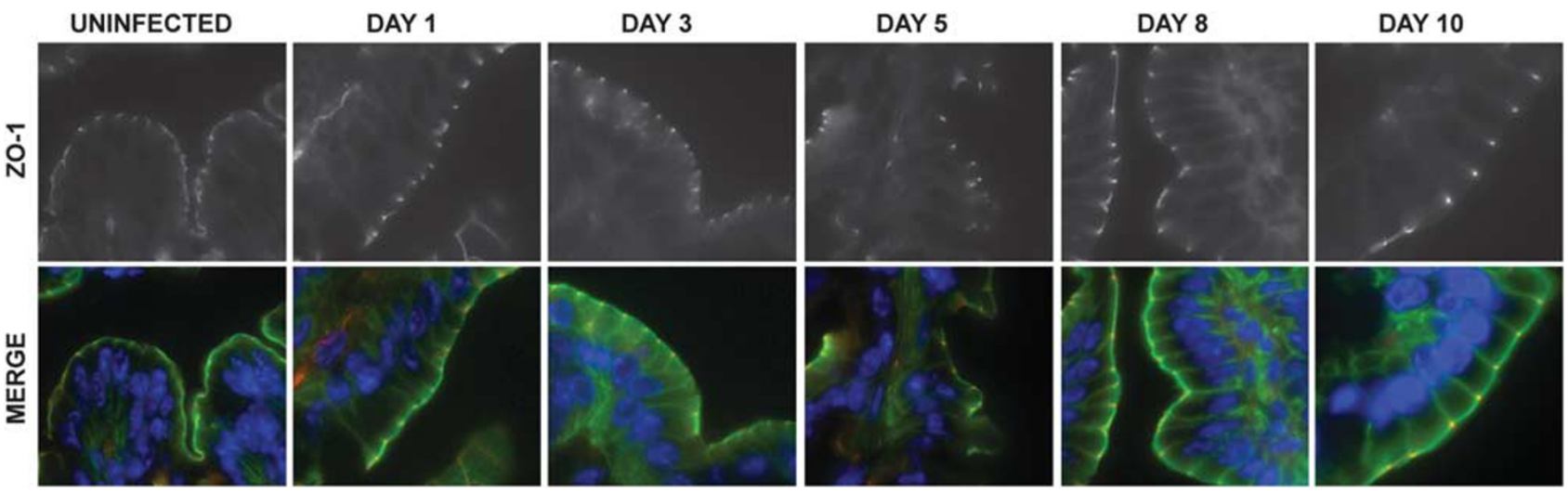

Figure 9 ZO-1 immunofluorescence microscopy of colonic tissues from uninfected and EHEC-infected C57BI/6J mice pretreated with streptomycin at days 1, 3, 5, 8, and 10 after infection. Merged image shows ZO-1 (red), actin (green), and Hoechst (blue) staining of colonic samples. 
UNINFECTED

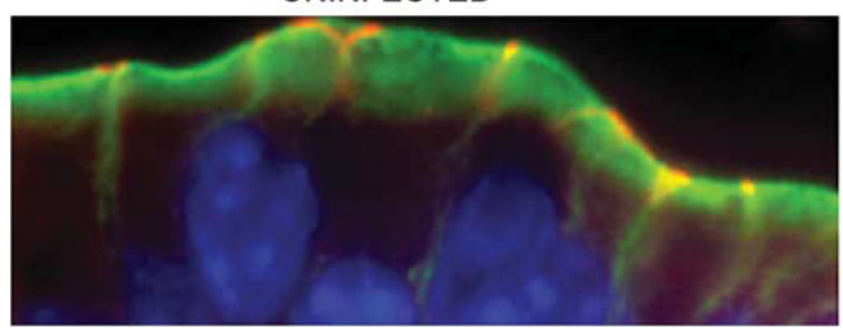

INFECTED

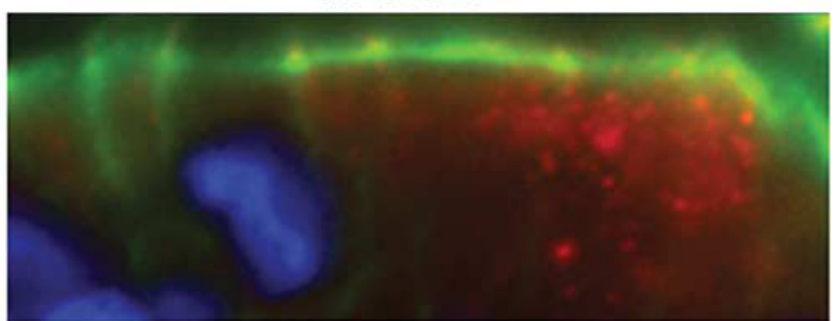

Figure 10 Occludin immunofluorescence microscopy of colonic tissues of uninfected and EHEC-infected C57BI/6J mice pretreated with streptomycin at day 5 after infection. Colonic tissues were stained for occludin (red), actin (green), and Hoechst (blue).
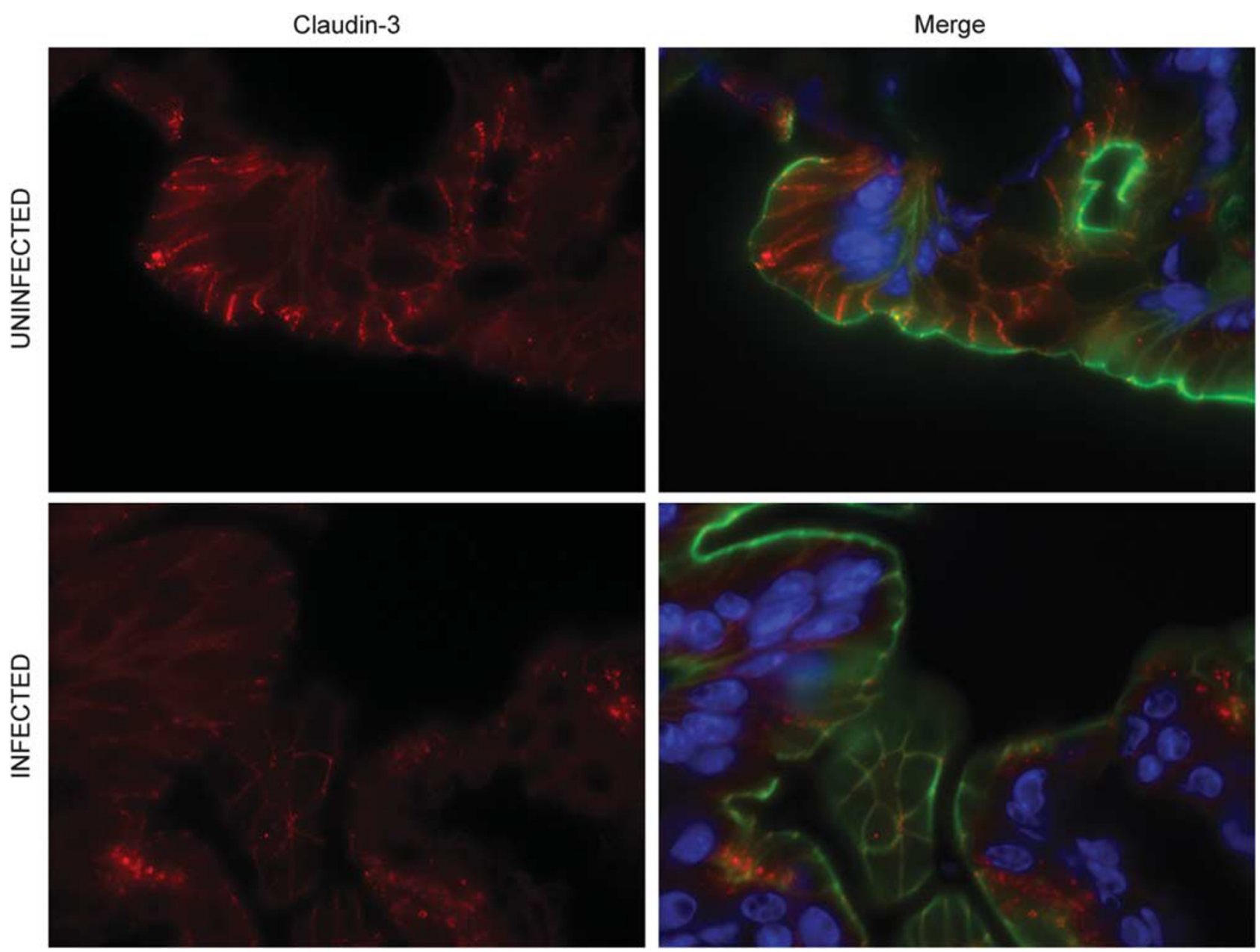

Figure 11 Claudin-3 immunofluorescence microscopy of colonic tissues of uninfected and EHEC-infected C57BI/6J mice pretreated with streptomycin at day 3 after infection. Merged image shows claudin-3 (red), actin (green), and Hoechst (blue) staining of colonic samples.

susceptible to streptomycin. To allow excretion of residual streptomycin, mice were allowed to recover for another $24 \mathrm{~h}$ after antibiotic treatment before infecting with EHEC.

We demonstrated in this study that EHEC adhere to and colonize the cecum and colon more efficiently than the small intestine. Although the mechanism of adherence was not assessed in this study, in vitro and some in vivo data suggest that fimbriae, ${ }^{31}$ outer membrane proteins, ${ }^{32}$ iha-encoded surface protein, ${ }^{33}$ and the TTSS ${ }^{15}$ have a role in this process. Previous studies have shown that intimin contributes to the colonization of EHEC O157:H7 in mice. Female BALB/c mice immunized with a plant cell-based intimin vaccine before infection exhibited reduced duration of EHEC O157:H7 shedding in the stool. ${ }^{34}$ In another study by 
O'Brien and coworkers, ${ }^{35}$ infection of female BALB/c mice with intimin-deletion mutant of EHEC O157:H7 resulted in decreased colonization as compared with infection with the intimin-positive EHEC strain. In addition to the multiple factors involved in adherence, colonization in mouse models is also dependent on the mouse strain as shown in a study by
Nagano et $a l,{ }^{15}$ wherein EHEC organisms were shown to effectively colonize ICR mice but not $\mathrm{BALB} / \mathrm{c}, \mathrm{C} 3 \mathrm{H} / \mathrm{HeN}$, $\mathrm{C} 3 \mathrm{H} / \mathrm{HeJ}$, and $\mathrm{A} / \mathrm{J}$ mice,

We also showed that EHEC infection results in the distortion and effacement of the microvilli. This correlates with actin rearrangement as observed in in vitro and in vivo

\section{Claudin-2}
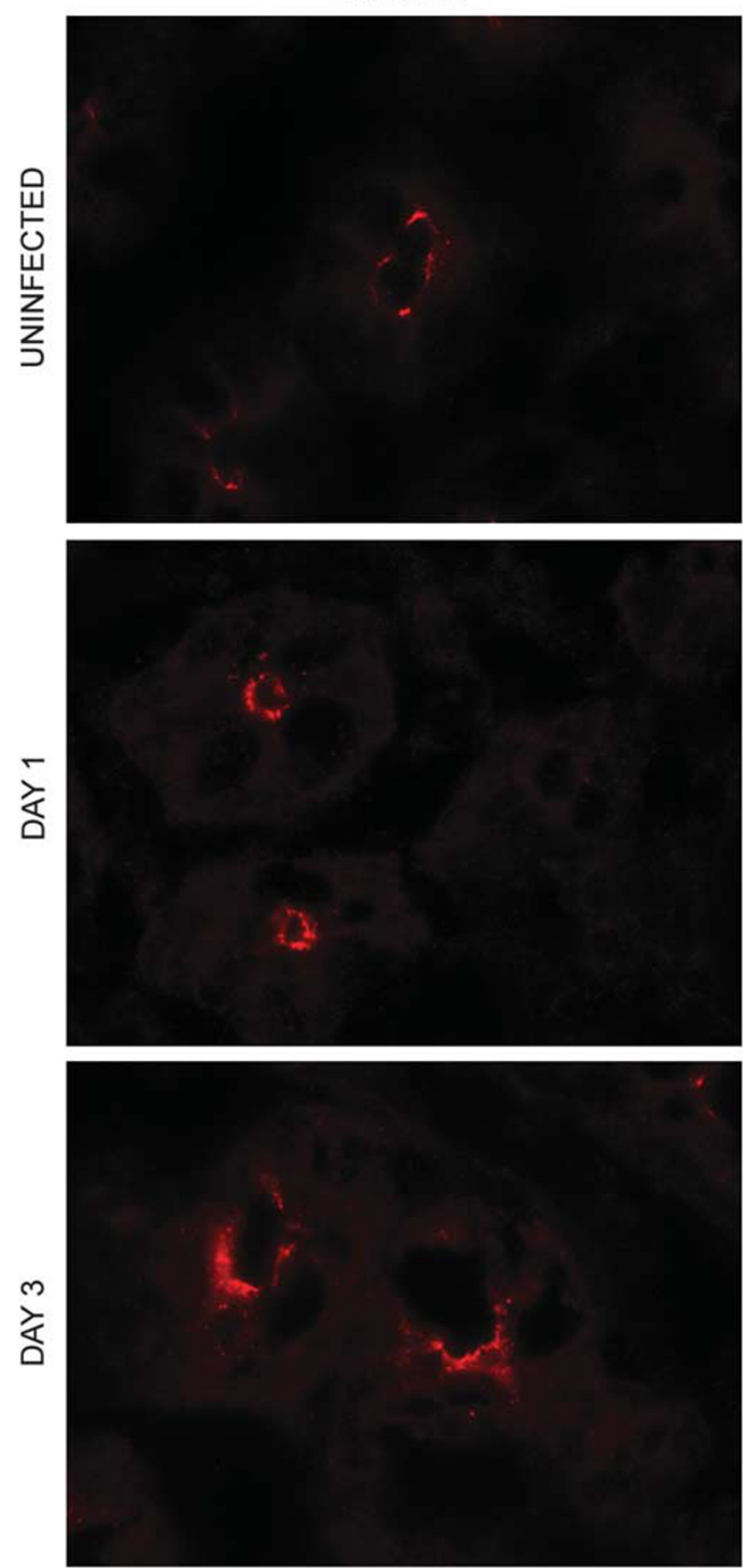

\section{Merge}
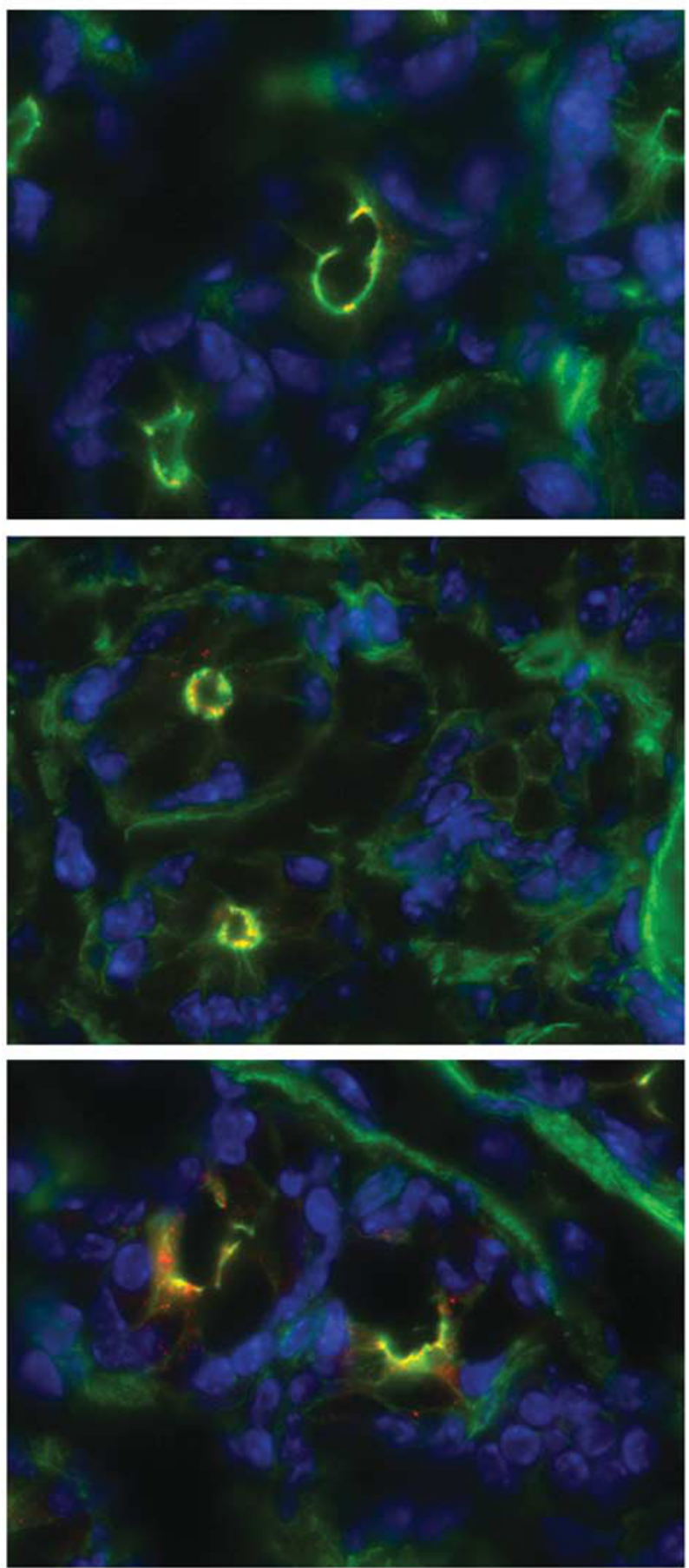

Figure 12 Claudin-2 immunofluorescence microscopy of colonic tissues from uninfected and EHEC-infected C57BI/6J mice pretreated with streptomycin at days $1,3,5,8$, and 10 after infection. Merged image shows claudin-2 (red), actin (green), and Hoechst (blue) staining of colonic samples. 

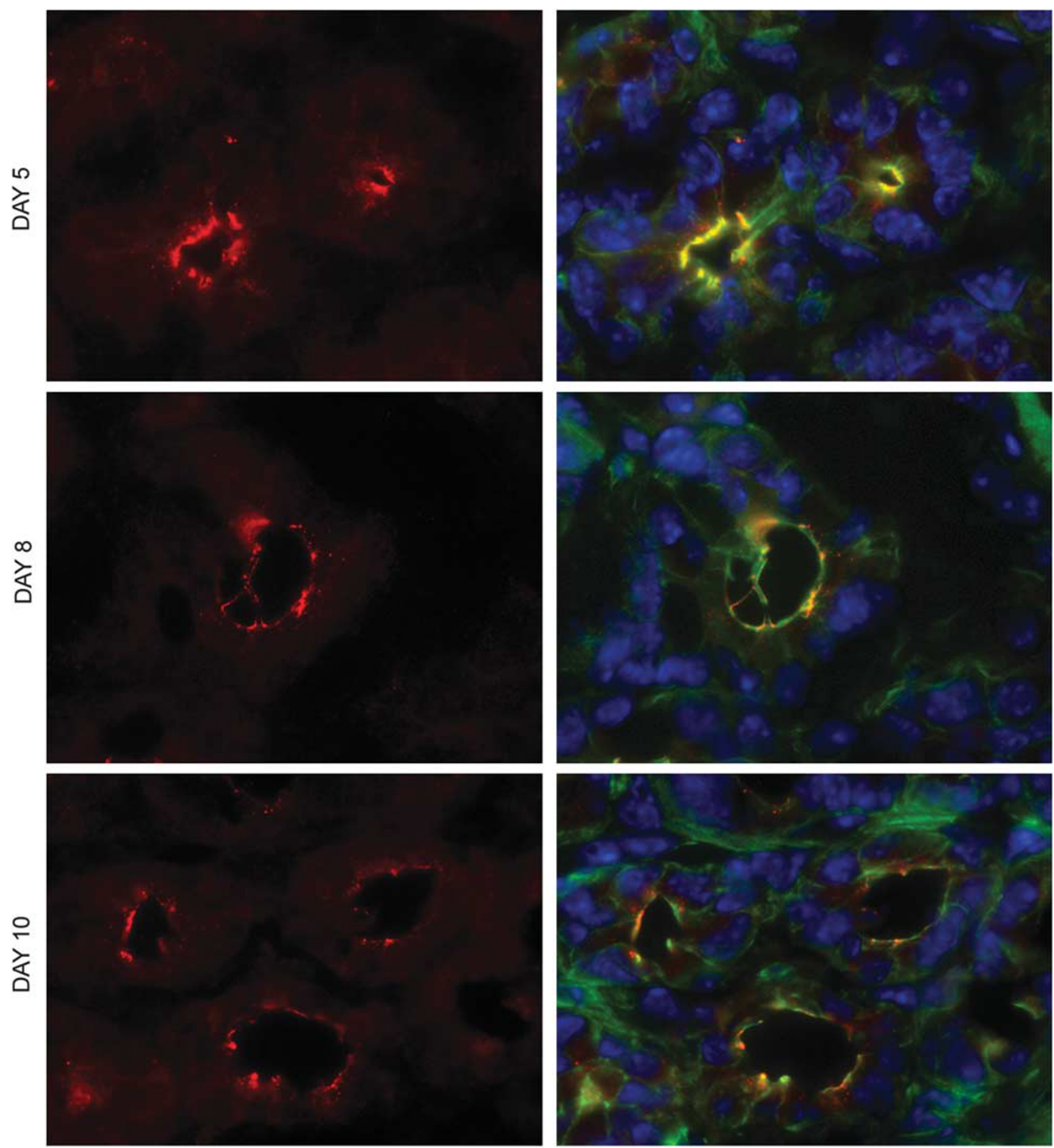

Figure 12 Continued.

studies. ${ }^{1,15}$ The effacement of microvilli and disruption of TJs by EHEC as shown in C57Bl/6 $\mathrm{J}$ mice has important clinical implications. Normally, intact microvilli structure and nonporous TJs help maintain the structural and physiological integrity of the gastrointestinal tract. Disruption of these homeostatic mechanisms of intestinal stability may contribute to the clinical effects of diarrhea as a consequence of EHEC infection.
Although EHEC induced localized effacement of microvilli, it was difficult to capture images of intimately attached bacteria and the well-characterized A/E lesions with pedestals because of modest levels of tissue-associated bacteria. However, whole-tissue imaging of infected bioluminescent EHEC indicates that the bacteria associate tightly with the cecum and colon. At present, it is not clear whether EHEC is able to induce microvilli effacement in the absence of intimately 


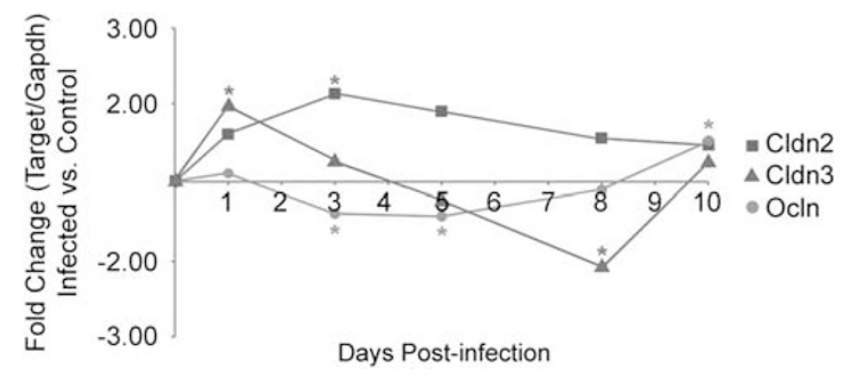

Figure 13 mRNA transcript levels of Cldn2, Cldn3, and Ocln present in colonic tissues of uninfected and EHEC-infected C57BI/6J mice pretreated with streptomycin at days 1, 3, 5, 8, and 10 after infection. Fold change of target mRNA copies per Gapdh mRNA copies of colon samples of EHECinfected mice compared with uninfected controls were determined. Values above the $x$ axis are positive fold changes, and values below the $x$ axis are negative fold changes. ${ }^{*}$ Indicates $P$-value $<0.05$ when daily target mRNA transcript levels present in colonic tissues of infected mice are compared with uninfected control mice.

attached bacteria in C57Bl/6J mice. Savkovic et $a l^{20}$ observed a similar phenotype in the enteropathogenic E. coli infection of $\mathrm{C} 57 \mathrm{Bl} / 6 \mathrm{~J}$ mice. In contrast, previous studies on C. rodentium infection of mice ${ }^{36,37}$ and EHEC infection of rabbits and piglets ${ }^{9,38,39}$ showed intimately attached bacteria and $\mathrm{A} / \mathrm{E}$ lesions with pedestals. The phenotypic differences between our model and those published for $C$. rodentium infection of mice and EHEC infection of rabbits and piglets may be due to differences in the bacteria, levels of colonizing bacteria, and hosts used.

Once colonization and adherence to the intestines of C57Bl/6J mice occurs, EHEC infection results in physiological and structural changes of intestinal epithelial cells. Our study showed alterations in these parameters by measuring TER and permeability to macromolecules and performing microscopic analysis of intestinal tissues. EHEC infection significantly reduced TER of the colon at 3 and 5 days after infection in the absence of antibiotics and at days 8 and 10 after infection in mice receiving streptomycin pretreatment. Although the decrease in TER in the colon of streptomycinpretreated mice occurs later compared with mice that did not receive antibiotics, this correlates with the bacterial growth expansion, which peaks at day 8 in streptomycin-pretreated mice. We also verified that the decrease in TER detected in infected mice was accompanied by an increase in mucosal permeability to macromolecules. We further showed that the electrophysiological changes in the colon correlates with alterations in TJ architecture. Although ZO-1 was not altered as a result of EHEC infection, the redistribution of occludin and claudin- 3 and increased expression of claudin- 2 observed by immunohistochemistry correlate with the reduced TER observed in the colon.

Most interestingly, we showed, for the first time, that EHEC infection induces changes in claudin-2 expression in the crypts of mouse colon. Claudin-2 has been previously identified as the electrically 'leaky' claudin ${ }^{40,41}$ and its elevated expression has been implicated in inflammatory bowel disease. $^{42,43}$ Expression of claudin-2 in CMT-93 and in MDCK cell lines was also shown to decrease TER. ${ }^{44,45}$ These previous studies corroborate our findings that elevated claudin-2 levels in the colon of EHEC-infected mice correlate with decreased TER.

We further showed that increased claudin-2 protein levels can be attributed to elevated amounts of mRNA transcripts. The half-life of claudin-2 protein expressed in MDCK cells is $\sim 12 \mathrm{~h}^{46}$ Hence, the increased claudin-2 protein levels we observed in our study are likely due to enhanced gene expression rather than protein accumulation.

Human CLDN2 and mouse Cldn2 gene promoters harbor binding sites for caudal-related homeobox ( $\mathrm{Cdx} 1$ and $\mathrm{Cdx} 2)$, hepatocyte-nuclear factor-1 alpha isoform $(\mathrm{Hnfl} \alpha)$, and Gata4 transcription factors. ${ }^{47}$ Mutagenesis and DNA-binding assays provided evidence that human CLDN2 promoter activity is positively regulated by $\mathrm{Cdx} 2$, as well as by $\operatorname{Hnfl} \alpha^{47,48}$ Forced expression of GATA4 in Caco-2 results in an increased claudin-2 expression. ${ }^{49}$ In addition, the human CLDN2 gene promoter has an NFkB-binding site and deletion of this site decreased promoter activity in transfected Caco- 2 cells. ${ }^{47}$ $\mathrm{NF \kappa B}$ is activated by $\mathrm{TNF} \alpha$, and high levels of $\mathrm{TNF} \alpha$ are associated with the development of intestinal inflammation in Crohn's disease. Interestingly, claudin-2 protein levels in human intestinal cell line HT-29 have been shown to increase in response to TNF $\alpha$, and this was found to be due to elevated CLDN2-specific mRNA and enhanced promoter activity. ${ }^{50}$ As EHEC also increases secretion of inflammatory cytokines, including $\mathrm{TNF} \alpha$, the increased $\mathrm{Cldn} 2$ gene expression we observed could either be due to a direct response to EHEC organisms or a secondary response to EHEC-induced TNF $\alpha$ secretion.

Claudin-3 is also upregulated in ulcerative colitisassociated colon carcinomas and in colorectal cancer. ${ }^{51,52}$ Increased expression of CLDN1,CLDN3, and CLDN4 in colorectal tumor tissues resulted in increased paracellular permeability and significant disorganization of TJ strands observed by freeze fracture replicas. ${ }^{52}$ CLDN3 knockdown by siRNA of human gastric adenocarcinoma cell line MKN28 decreased TER..$^{53}$ In our study, low Cldn3 mRNA transcripts levels, combined with increased Cldn2 mRNA transcript levels, correlates with decreased TER at day 8 after infection.

In addition to electrophysiological changes and alterations in the distribution and expression of TJ proteins, EHEC also induced mild inflammation as indicated by the increase in polymorphonuclear leukocytes at the lamina propria of the colonic tissues at day 3 after infection. It has been published previously that both EHEC and enteropathogenic E. coli attenuate the host immune response to infection. ${ }^{54-56}$ Stx is also known to be proinflammatory ${ }^{57,58}$ but in our model system, we used a Stx-negative strain. Hence, the lack of robust inflammatory phenotype in our study is not surprising.

In conclusion, our data show that $\mathrm{C} 57 \mathrm{Bl} / 6 \mathrm{~J}$ mice are susceptible to infection by EHEC and serve as an appropriate 
in vivo model to establish the consequences of EHEC infection and define the role of specific EHEC effector molecules in pathogenesis.

\section{ACKNOWLEDGEMENTS}

This study was supported by grants R01 DK058694 and P01 DK067887 from the National Institute of Health to GH and by a Veterans Affairs Merit Award to GH. KJR is supported by the Crohn's and Colitis Foundation of America.

\section{DISCLOSURE/CONFLICT OF INTEREST}

The authors declare no conflict of interest.

1. Frankel G, Phillips $A D$, Rosenshine I, et al. Enteropathogenic and enterohaemorrhagic Escherichia coli: more subversive elements. Mol Microbiol 1998;30:911-921.

2. McDaniel TK, Kaper JB. A cloned pathogenicity island from enteropathogenic Escherichia coli confers the attaching and effacing phenotype on E. coli K-12. Mol Microbiol 1997;23:399-407.

3. Bielaszewska $M$, Karch $H$. Consequences of enterohaemorrhagic Escherichia coli infection for the vascular endothelium. Thromb Haemost 2005;94:312-318.

4. Nataro JP, Kaper JB. Diarrheagenic Escherichia coli. Clin Microbiol Rev 1998;11:142-201.

5. Viswanathan VK, Koutsouris A, Lukic $\mathrm{S}$, et al. Comparative analysis of EspF from enteropathogenic and enterohemorrhagic Escherichia coli in alteration of epithelial barrier function. Infect Immun 2004;72:3218-3227.

6. Hecht G, Marrero JA, Danilkovich A, et al. Pathogenic Escherichia coli increase $\mathrm{Cl}$ - secretion from intestinal epithelia by upregulating galanin-1 receptor expression. J Clin Invest 1999;104:253-262.

7. Beery JT, Doyle MP, Schoeni JL. Colonization of chicken cecae by Escherichia coli associated with hemorrhagic colitis. Appl Environ Microbiol 1985;49:310-315.

8. Potter ME, Kaufmann AF, Thomason $B M$, et al. Diarrhea due to Escherichia coli O157:H7 in the infant rabbit. J Infect Dis 1985;152:1341-1343.

9. Pai $\mathrm{CH}$, Kelly JK, Meyers GL. Experimental infection of infant rabbits with verotoxin-producing Escherichia coli. Infect Immun 1986;51: $16-23$.

10. Francis DH, Moxley RA, Andraos CY. Edema disease-like brain lesions in gnotobiotic piglets infected with Escherichia coli serotype 0157:H7. Infect Immun 1989;57:1339-1342.

11. Tzipori S, Gunzer F, Donnenberg MS, et al. The role of the eaeA gene in diarrhea and neurological complications in a gnotobiotic piglet model of enterohemorrhagic Escherichia coli infection. Infect Immun 1995;63:3621-3627.

12. Isogai $E$, Isogai $H$, Takeshi $K$, et al. Protective effect of Japanese green tea extract on gnotobiotic mice infected with an Escherichia coli O157:H7 strain. Microbiol Immunol 1998;42:125-128.

13. Kurioka $T$, Yunou Y, Kita E. Enhancement of susceptibility to Shiga toxin-producing Escherichia coli O157:H7 by protein calorie malnutrition in mice. Infect Immun 1998:66:1726-1734.

14. Ogawa M, Shimizu K, Nomoto K, et al. Protective effect of Lactobacillus casei strain Shirota on Shiga toxin-producing Escherichia coli O157:H7 infection in infant rabbits. Infect Immun 2001:69:1101-1108.

15. Nagano K, Taguchi K, Hara T, et al. Adhesion and colonization of enterohemorrhagic Escherichia coli O157:H7 in cecum of mice. Microbiol Immunol 2003;47:125-132.

16. Tzipori $\mathrm{S}$, Karch $\mathrm{H}$, Wachsmuth $\mathrm{Kl}$, et al. Role of a 60-megadalton plasmid and Shiga-like toxins in the pathogenesis of infection caused by enterohemorrhagic Escherichia coli $0157: \mathrm{H7}$ in gnotobiotic piglets. Infect Immun 1987;55:3117-3125.

17. Myhal ML, Laux DC, Cohen PS. Relative colonizing abilities of human fecal and K 12 strains of Escherichia coli in the large intestines of streptomycin-treated mice. Eur J Clin Microbiol 1982;1:186-192.

18. Morin CE, Kaper JB. Use of stabilized luciferase-expressing plasmids to examine in vivo-induced promoters in the Vibrio cholerae vaccine strain CVD 103-HgR. FEMS Immunol Med Microbiol 2009;57:69-79.
19. Wiles S, Pickard KM, Peng K, et al. In vivo bioluminescence imaging of the murine pathogen Citrobacter rodentium. Infect Immun 2006;74:5391-5396.

20. Savkovic SD, Villanueva J, Turner JR, et al. Mouse model of enteropathogenic Escherichia coli infection. Infect Immun 2005;73:1161-1170.

21. Shifflett DE, Clayburgh DR, Koutsouris $A$, et al. Enteropathogenic E. coli disrupts tight junction barrier function and structure in vivo. Lab Invest 2005;85:1308-1324.

22. Mead PS, Griffin PM. Escherichia coli O157:H7. Lancet 1998;352: 1207-1212.

23. Shimizu K, Asahara T, Nomoto K, et al. Development of a lethal Shiga toxin-producing Escherichia coli-infection mouse model using multiple mitomycin C treatment. Microb Pathog 2003;35:1-9.

24. Wadolkowski EA, Burris JA, O'Brien AD. Mouse model for colonization and disease caused by enterohemorrhagic Escherichia coli O157:H7. Infect Immun 1990;58:2438-2445.

25. Mundy R, Girard F, FitzGerald AJ, et al. Comparison of colonization dynamics and pathology of mice infected with enteropathogenic Escherichia coli, enterohaemorrhagic E. coli and Citrobacter rodentium. FEMS Microbiol Lett 2006;265:126-132.

26. Que JU, Hentges DJ. Effect of streptomycin administration on colonization resistance to Salmonella typhimurium in mice. Infect Immun 1985;48:169-174.

27. Que JU, Casey SW, Hentges DJ. Factors responsible for increased susceptibility of mice to intestinal colonization after treatment with streptomycin. Infect Immun 1986;53:116-123.

28. Lye DJ. A mouse model for characterization of gastrointestinal colonization rates among environmental Aeromonas isolates. Curr Microbiol 2009;58:454-458.

29. Bohnhoff M, Miller CP, Martin WR. Resistance of the mouse's intestinal tract to experimental Salmonella infection. I. Factors which interfere with the initiation of infection by oral inoculation. J Exp Med 1964;120:805-816.

30. Bohnhoff M, Miller CP, Martin WR. Resistance of the mouse's intestinal tract to experimental Salmonella infection. li. Factors responsible for its loss following streptomycin treatment. J Exp Med 1964;120: 817-828.

31. Karch $\mathrm{H}$, Heesemann J, Laufs $\mathrm{R}$, et al. A plasmid of enterohemorrhagic Escherichia coli 0157:H7 is required for expression of a new fimbrial antigen and for adhesion to epithelial cells. Infect Immun 1987;55: 455-461.

32. Zhao S, Meng J, Doyle MP, et al. A low molecular weight outermembrane protein of Escherichia coli 0157: $\mathrm{H} 7$ associated with adherence to INT407 cells and chicken caeca. J Med Microbiol 1996:45:90-96

33. Tarr PI, Bilge SS, Vary Jr JC, et al. Iha: a novel Escherichia coli 0157:H7 adherence-conferring molecule encoded on a recently acquired chromosomal island of conserved structure. Infect Immun 2000;68:1400-1407.

34. Judge NA, Mason HS, O'Brien AD. Plant cell-based intimin vaccine given orally to mice primed with intimin reduces time of Escherichia coli O157:H7 shedding in feces. Infect Immun 2004;72:168-175.

35. Sinclair JF, Dean-Nystrom EA, O'Brien AD. The established intimin receptor Tir and the putative eucaryotic intimin receptors nucleolin and beta1 integrin localize at or near the site of enterohemorrhagic Escherichia coli 0157:H7 adherence to enterocytes in vivo. Infect Immun 2006;74:1255-1265.

36. Mundy R, MacDonald TT, Dougan G, et al. Citrobacter rodentium of mice and man. Cell Microbiol 2005;7:1697-1706.

37. Klapproth JM, Sasaki M, Sherman $M$, et al. Citrobacter rodentium lifA/efa1 is essential for colonic colonization and crypt cell hyperplasia in vivo. Infect Immun 2005;73:1441-1451.

38. Dean-Nystrom EA, Melton-Celsa AR, Pohlenz JF, et al. Comparative pathogenicity of Escherichia coli $\mathrm{O} 157$ and intimin-negative non-O157 Shiga toxin-producing $E$ coli strains in neonatal pigs. Infect Immun 2003;71:6526-6533.

39. Sherman P, Soni R, Karmali M. Attaching and effacing adherence of Vero cytotoxin-producing Escherichia coli to rabbit intestinal epithelium in vivo. Infect Immun 1988;56:756-761.

40. Furuse M, Furuse K, Sasaki H, et al. Conversion of zonulae occludentes from tight to leaky strand type by introducing claudin-2 into Madin-Darby canine kidney I cells. J Cell Biol 2001;153:263-272. 
41. Amasheh $\mathrm{S}$, Meiri N, Gitter $\mathrm{AH}$, et al. Claudin-2 expression induces cation-selective channels in tight junctions of epithelial cells. J Cell Sc 2002;115:4969-4976.

42. Weber CR, Nalle SC, Tretiakova M, et al. Claudin-1 and claudin-2 expression is elevated in inflammatory bowel disease and may contribute to early neoplastic transformation. Lab Invest 2008;88:1110-1120.

43. Zeissig S, Burgel N, Gunzel D, et al. Changes in expression and distribution of claudin 2, 5 and 8 lead to discontinuous tight junctions and barrier dysfunction in active Crohn's disease. Gut 2007;56:61-72.

44. Van Itallie CM, Holmes J, Bridges A, et al. The density of small tight junction pores varies among cell types and is increased by expression of claudin-2. J Cell Sci 2008;121:298-305.

45. Inai $T$, Sengoku A, Hirose $E$, et al. Comparative characterization of mouse rectum CMT93-I and -II cells by expression of claudin isoforms and tight junction morphology and function. Histochem Cell Biol 2008;129:223-232.

46. Van Itallie CM, Colegio OR, Anderson JM. The cytoplasmic tails of claudins can influence tight junction barrier properties through effects on protein stability. J Membr Biol 2004;199:29-38.

47. Sakaguchi T, Gu X, Golden HM, et al. Cloning of the human claudin-2 5 '-flanking region revealed a TATA-less promoter with conserved binding sites in mouse and human for caudal-related homeodomain proteins and hepatocyte nuclear factor-1alpha. J Biol Chem 2002;277:21361-21370.

48. Mankertz J, Hillenbrand B, Tavalali S, et al. Functional crosstalk between Wnt signaling and Cdx-related transcriptional activation in the regulation of the claudin- 2 promoter activity. Biochem Biophys Res Commun 2004;314:1001-1007.

49. Escaffit F, Boudreau F, Beaulieu JF. Differential expression of claudin-2 along the human intestine: implication of GATA-4 in the maintenance of claudin-2 in differentiating cells. J Cell Physiol 2005;203:15-26.
50. Mankertz J, Amasheh M, Krug SM, et al. TNFalpha up-regulates claudin2 expression in epithelial HT-29/B6 cells via phosphatidylinositol-3kinase signaling. Cell Tissue Res 2009;336:67-77.

51. de Oliveira SS, de Oliveira IM, De Souza W, et al. Claudins upregulation in human colorectal cancer. FEBS Lett 2005;579:6179-6185.

52. Mees ST, Mennigen R, Spieker T, et al. Expression of tight and adherens junction proteins in ulcerative colitis associated colorectal carcinoma: upregulation of claudin-1, claudin-3, claudin-4, and beta-catenin. Int J Colorectal Dis 2009;24:361-368.

53. Hashimoto $\mathrm{K}$, Oshima $\mathrm{T}$, Tomita $\mathrm{T}$, et al. Oxidative stress induces gastric epithelial permeability through claudin-3. Biochem Biophys Res Commun 2008;376:154-157.

54. Hauf N, Chakraborty T. Suppression of NF-kappa B activation and proinflammatory cytokine expression by Shiga toxin-producing Escherichia coli. J Immunol 2003;170:2074-2082.

55. Sharma R, Tesfay S, Tomson FL, et al. Balance of bacterial pro- and anti-inflammatory mediators dictates net effect of enteropathogenic Escherichia coli on intestinal epithelial cells. Am J Physiol Gastrointest Liver Physiol 2006;290:G685-G694.

56. Bellmeyer A, Cotton C, Kanteti R, et al. Enterohemorrhagic Escherichia coli suppresses inflammatory response to cytokines and its own toxin. Am J Physiol Gastrointest Liver Physiol 2009;297: G576-G581.

57. Ritchie JM, Thorpe $\mathrm{CM}$, Rogers $\mathrm{AB}$, et al. Critical roles for stx2, eae, and tir in enterohemorrhagic Escherichia coli-induced diarrhea and intestinal inflammation in infant rabbits. Infect Immun 2003;71: 7129-7139.

58. Yamasaki C, Natori Y, Zeng XT, et al. Induction of cytokines in a human colon epithelial cell line by Shiga toxin 1 (Stx1) and Stx2 but not by non-toxic mutant Stx 1 which lacks N-glycosidase activity. FEBS Lett 1999:442:231-234 